\title{
Excess Coenzyme A Reduces Skeletal Muscle Performance and Strength in Mice Overexpressing Human PANK2
}

Deborah R. Corbin\#, Jerold E. Rehg ${ }^{\S}$, Danielle L. Shepherd, Peter Stoilov\#, Ryan J. Percifield ${ }^{\&}$, Linda Horner $^{\$}$, Sharon Frase ${ }^{\$}$, Yong-Mei Zhang ${ }^{\ddagger 1}$, Charles O. Rock ${ }^{\ddagger}$, John M. Hollander ${ }^{\ddagger}$, Suzanne Jackowski and Roberta Leonardi ${ }^{\# 2}$

From the Departments of Biochemistry ${ }^{\#}$, Exercise Physiology ${ }^{\sharp}$, and Biology \&, West Virginia University, Morgantown, WV 26506, USA and the Departments of Infectious Diseases ${ }^{\ddagger}$ and Pathology ${ }^{\S}$, and the Cell and Tissue Imaging-Electron Microscopy Shared Resource\$, St. Jude Children's Research Hospital, Memphis, TN 38105, USA

${ }^{1}$ Present address: Jeneil Biotech Inc, Saukville, WI 53080;

${ }^{2}$ To whom correspondence should be addressed: Department of Biochemistry, West Virginia University, Morgantown, WV 26506, USA. Email address: roleonardi@hsc.wvu.edu 
Abstract Coenzyme $A(C o A)$ is a cofactor that is central to energy metabolism and CoA synthesis is controlled by the enzyme pantothenate kinase (PanK). A transgenic mouse strain expressing human PANK2 was derived to determine the physiological impact of PANK overexpression and elevated CoA levels. The $\operatorname{Tg}(P A N K 2)$ mice expressed high levels of the transgene in skeletal muscle and heart; however, CoA was substantially elevated only in skeletal muscle, possibly associated with the comparatively low endogenous levels of acetyl-CoA, a potent feedback inhibitor of PANK2. $\operatorname{Tg}(P A N K 2)$ mice were smaller, had less skeletal muscle mass and displayed significantly impaired exercise tolerance and grip strength. Skeletal myofibers were characterized by centralized nuclei and aberrant mitochondria. Both the content of fully assembled complex I of the electron transport chain and ATP levels were reduced, while markers of oxidative stress were elevated in $\operatorname{Tg}(P A N K 2)$ skeletal muscle. These abnormalities were not detected in the $\operatorname{Tg}(P A N K 2)$ heart muscle, with the exception of spotty loss of cristae organization in the mitochondria. The data demonstrate that excessively high CoA may be detrimental to skeletal muscle function.

Keywords: Coenzyme A, muscle, mitochondria, transgenic mice, pantothenate kinase 


\section{Introduction}

Coenzyme A (CoA) is the major acyl group carrier in biology and an indispensable substrate cofactor for hundreds of reactions. Along with its thioesters, CoA participates in a multitude of metabolic processes, including fatty acid and lipid synthesis, fatty acid degradation, ketone body metabolism and the tricarboxylic acid cycle (1). CoA is assembled in five steps from the vitamin pantothenate, cysteine and ATP. The first and rate-limiting step in CoA synthesis is the phosphorylation of pantothenate to phosphopantothenate (2-4) catalyzed by pantothenate kinase (PanK). PanK activity is regulated through feedback inhibition by CoA and acyl-CoAs, providing a key mechanism to modulate CoA synthesis and maintain cellular CoA homeostasis (57). The steady state levels of tissue CoA can also be affected by degradation, but CoA-degrading enzymes have a narrow tissue distribution as they are predominantly expressed in liver and kidneys (8,9). Mammals contain four active PanK isoforms, PanK1 $\alpha$, PanK1 $\beta$, PanK2 and PanK3 (1), which provide some functional redundancy. The PanK $1 \alpha$ and $\beta$ isoforms are derived from a single gene via alternate initiation exons (6), and PanK2 and PanK3 are encoded by distinct genes $(2,10)$. The PanK isoforms differ in their tissue abundance, subcellular localizations and responses to feedback regulation, with PanK2 and PanK3 being the most stringently inhibited by CoA species $(2,6,11)$. Knockout mice have been instrumental to begin unraveling the role of $\mathrm{CoA}$ in metabolic regulation and the relative contribution of the PanK isoforms to the tissue-specific control of CoA content. Pank1 is highly expressed in liver (12) and Pank $1^{-/-}$mice show a 40\% reduction in liver CoA that leads to a deficit in fatty acid oxidation, impaired gluconeogenesis and fasting hypoglycemia (13). Pank2 knockout mice have defective sperm production $(14,15)$, consistent with PanK2 being the most abundant isoform expressed in mouse testes. The Pank $1^{-/-}$Pank $2^{-/-}$double knockout mice have low CoA in liver and brain, exhibit a severe metabolic phenotype related to reduced fatty acid and ketone oxidation and do not survive to weaning (15). Taken together, these data demonstrate the impact of reducing the intracellular levels of CoA on metabolism and organ function.

In humans, PANK2 is highly expressed in the brain (16), and mutations in the PANK2 gene result in Pantothenate Kinase-Associated Neurodegeneration (PKAN) (10), a childhood onset disease that leads to dystonia, parkinsonism, dementia and ultimately death. Many of the PKAN mutations are predicted to result in truncated proteins or severely reduced enzymatic activity, but several point mutations either maintain or only partially reduce enzyme activity (11), while other mutations destabilize the protein and promote PANK2 protein degradation $(17,18)$. The underlying pathology of PKAN is attributed to reduced CoA in the central nervous system, a conclusion supported by the recent finding that missense mutations in human CoA synthase, the last enzyme in the CoA biosynthetic pathway, also give rise to PKAN-like symptoms (19). Additionally, mice with increased CoA degradation in neurons exhibit reduced motor coordination, one of the hallmarks of PKAN disease (20). Although PKAN is still currently untreatable, progress has been made towards finding strategies to overcome the PANK2 blockade and increase cellular CoA levels. Phosphopantetheine, a CoA precursor downstream of the PanK reaction, was recently shown to improve the phenotype of cell lines and mutant flies 
with reduced CoA (21). Administration of unmodified phosphopantothenate, the product of the PanK reaction, was not able to bypass the genetic deletion of mouse Pank1; however, derivatization of phosphopantothenate with aryl phosphoroamidate groups allowed for tissue delivery and cellular uptake, increasing hepatic CoA levels in the Pank1/- mice (4). In particular, the modified phosphopantothenate molecule raised CoA above the physiological levels found in wild-type mice in a dose-dependent manner, confirming PanK as the major regulatory step in the pathway. Although the physiological consequences of reduced tissue CoA have been studied, the effects of excess CoA on cellular processes are currently unknown.

The goal of this study was to investigate the physiological consequences of increasing tissue CoA levels. In our model, the concentration of CoA was artificially raised by constructing a transgenic mouse strain that expressed the human PANK2 gene. Unlike the other PANKs, human PANK2 protein has an amino terminus that distinguishes it from the mouse isoforms and a recently described PANK2-specific antibody allowed us to readily detect expression (22). The results show that PANK2 overexpression elevated the concentration of CoA in skeletal muscle leading to altered mitochondrial morphology, reduced levels of fully assembled complex I of the mitochondrial electron transport chain (ETC) and reduced complex I activity, lower ATP content and increased oxidative stress in this tissue compared to non-transgenic and matched control mice. The combined molecular alterations of the skeletal muscle in the $\operatorname{Tg}(P A N K 2)$ mice resulted in a significant decrease in exercise tolerance and grip strength. These data underscore the importance of the physiological regulation of tissue CoA content.

\section{Experimental Procedures}

\subsection{Materials}

Reagents were purchased from the following suppliers: primers from ThermoFisher Scientific, restriction enzymes and DNA polymerases from either Promega or New England Biolabs, D-[1- ${ }^{14}$ C]pantothenic acid (50 $\mathrm{mCi} / \mathrm{mmol}$ ) from American Radiolabeled Chemicals, antibodies against Ndufa9 and cyclophilin D from Abcam and ThermoFisher Scientific, respectively. The rabbit antibody against human PANK2 was previously described (22). All primary antibodies were used at 1:1,000 dilution. HRP-conjugated anti-mouse and antirabbit IgG secondary antibodies were purchased from ThermoFisher Scientific and used at a 1:50,000 dilution. All other reagents were of analytical grade or better and were purchased from Sigma-Aldrich or Fisher Scientific unless otherwise stated.

\subsection{Animals}

Mice were maintained at a room temperature of $72 \pm 2{ }^{\circ} \mathrm{F}$, room humidity of $50 \% \pm 10 \%$, a 14 -hr light, 10 -hr dark cycle, with the dark cycle starting at 20:00 hr, and fed a regular rodent diet (LabDiet 5013). Blood was drawn either by retro-orbital bleeding or by cardiac puncture. To determine food intake, mice (3-4/cage) had unrestricted access to a pre-weighed amount of food, and residual chow was measured every $24 \mathrm{~h}$ for 4 days. Food intake was calculated as the difference between food provided and food left over in each cage after $24 \mathrm{~h}$; 
the data were averaged and reported as amount of food eaten per $24 \mathrm{~h}$ per mouse. Male mice, age 10-16 weeks, were used for all measurements (except Figure 2, which includes data from females). Serum analytes were measured in the St. Jude Veterinary Pathology Core facility, with the exception of creatine phosphokinase activity which was measured using the general method described by Oliver (23). Oxygen consumption $\left(\mathrm{VO}_{2}\right)$ and carbon dioxide production $\left(\mathrm{VCO}_{2}\right)$ were determined using a 4-chamber Oxymax system (Columbus Instruments) as previously described (24). All procedures were performed according to protocols approved by the St. Jude Children's Research Hospital Institutional Animal Care and Use Committee. Mice transferred to West Virginia University for the analyses conducted on isolated mitochondria were maintained at a room temperature of $72.0 \pm 0.3^{\circ} \mathrm{F}$, room humidity of $40 \% \pm 2 \%$, and a 12 -hr light, $12-\mathrm{hr}$ dark cycle, with the dark cycle starting at 18:00 hr. The mice were allowed to acclimate for at least 2 weeks before euthanasia according to protocols approved by the West Virginia University Institutional Animal Care and Use Committee.

\subsection{Derivation of transgenic mice}

The hybrid cytomegalovirus early enhancer/chicken $\beta$-actin/rabbit $\beta$-globin (CAG) promoter (25) was used to drive expression of human PANK2. The CAG promoter was excised with Pacl from the rosa26-CAG/tomato plasmid (kind gift of Jian Zuo, St. Jude Children's Research Hospital), blunt-ended with Klenow DNA polymerase, and subcloned into EcoRV-restricted pcDNA3.1(-) (ThermoFisher Scientific). The CAG promoter was then further subcloned into the $\mathrm{pCl}$ plasmid (Promega) within Xhol-Kpnl sites to generate the pCl-CAG plasmid. The PANK2 gene was amplified using forward primer 5'gggtaccaccATGgGGAGGCTCGGGCCCTTCCAC, $\quad$ reverse $\quad$ primer ccccgggtcacttatcgtcgtcatccttgtaatctcctccCGGGATCTTCAACAGCTCAAGG and the pKM4 plasmid as a template (11). The forward primer introduced a unique Kpnl restriction site (underlined sequence) and a perfect Kozak sequence (accATGg). The reverse primer introduced a Smal restriction site (underlined sequence) and a FLAG tag (italics) preceded by a GlyGly linker. The PCR product was ligated into PCR-BluntII-TOPO (Life Technologies), and its sequence confirmed by DNA sequencing. The PANK2 gene was then excised with EcoRI, blunt-ended with the Klenow fragment, and further digested with Kpnl before being ligated into the pCl-CAG plasmid within Kpnl/Smal sites. The final construct was named pPJ416. pPJ416 was restricted with Nhel and Clal, and the excised 3.8-kb fragment containing the CAG promoter, PANK2 and the SV40 late poly(A) signal was used to transfect HEK-293T cells. Robust transgene expression from the construct was confirmed by measuring PanK activity in cell lysates, using non-transfected cells as negative control (not shown). The same linearized DNA was used to generate transgenic founders by pronuclear injection into FVB/N fertilized eggs (Transgenic/Gene Knockout facility, St. Jude Children's Research Hospital). Mice were genotyped using primers specific for the transgene, CAG3'-For (5'-CGGCTTCTGGCGTGTGAC) and hPanK2-ScnR (5'-ggaggaagagaaggcggtgtag), and primers for ethanolamine kinase 2 were used as internal control, EKI2Scn-For (5'-CTCCTGGGACCTGTAATGACC) and EKI2Scn-Rev 
ATGCATCTTATGCCAGAGCG). Mice positive for the transgene showed a product of $285 \mathrm{bp}$, in addition to the 220-bp band from the internal control. A single $\mathrm{Tg}(P A N K 2)$ founder line was obtained. $\operatorname{Tg}(P A N K 2)$ mice were maintained as hemizygous through breeding with C57BL/6J mice (Jackson Laboratories), and littermates lacking the transgene were used as the control animals. Litters from breeding pairs of hemizygous $\operatorname{Tg}(P A N K 2)$ mice yielded homozygous transgenic animals. These data indicate that the homozygous animals were viable.

\subsection{Next generation sequencing and transgene mapping}

To determine the insertion site(s) of the transgene, a DNA library was prepared by the West Virginia University Genomics Core from isolated genomic DNA using the Illumina Nextera XT kit as per manufacturer's instructions. The average fragment size in the library was $679 \mathrm{bp}$ (200-2000 bp range). A pilot sequencing run on Illumina MiSeq sequencer produced 8,266,780 paired 76 nucleotide reads. The library was subsequently sequenced on Illumina HiSeq 1500 (Marshal University Genomics Core) to produce 342,754,288 paired 101 nucleotide reads. The coverage of the mouse genome by sequencing reads was 6.4 fold. Hisat 2 was used to map the reads to the sequence of the 3845 bp PANK2 construct that was used to generate the $\operatorname{Tg}(P A N K 2)$ mice (26). Read pairs where one mate was mapped to the construct and the second mate was not were extracted, and the unmapped mates were aligned to the transgene construct and to the mouse genome. These alignments identified four groups of reads: (i) reads aligned completely to the mouse genome; (ii) reads that aligned to the mouse genome and to the PANK2 construct, thus spanning the insertion point; (iii) reads that aligned to the begining and the end of the PANK2 construct, thus spanning the junctions of consecutive transgene copies in head-to-tail orientation; (iv) reads that failed the initial mapping due to low quality or the presence of untrimmed adapter sequences. The first three groups of reads were used to identify the insertion points and deduce the structure of the PANK2 locus. Additionally, Hisat2 was used to map all reads to the GRCm38 assembly of the mouse genome in order to estimate the depth of the coverage of the genome by the mappable reads.

The insertion sites were confirmed by PCR amplification, followed by Sanger sequencing. The following primers were used: TGi1_mm_For (5'-TGAGGCTTTGAAGACCACAG-3') and TGi1_tgL_Rev (5'TCTCGCTTCTCCTTGCTCAT-3') to amplify the left arm of insertion 1; TGi1_tgR_For (5'TCGTGGAGATAGCACCAAAG-3') and TGi1_mm_Rev (5'-CCCTCCTGGTAGGAAAGACA-3') to amplify the right arm of insertion 1; TGi2_tgR_For (5'-GGGCGTACTTGGCATATGAT-3') and TGi2_mm_Rev (5'GGGTCTGCTGACTCCATCTT-3') to amplify the right arm of insertion 2. Primers TGi1_mm_For, TGi1_tgL_Rev and TGi1_mm_Rev were also used in multiplex PCR reactions to determine the genotype of pups obtained from breeding hemizygous $\mathrm{Tg}(P A N K 2)$ males to hemizygous $\operatorname{Tg}($ PANK2) females, with a $553 \mathrm{bp}$ band indicating the presence of the transgene and a band at $364 \mathrm{bp}$ indicating the presence of a wild-type allele. 


\subsection{Quantitative real-time RT-qPCR}

Transcript abundance for enzymes of interest was determined using a procedure and primers previously described $(13,15)$. Sequences of primer pairs for additional targets are listed in Table S1. Relative mitochondrial copy number to nuclear copy number was determined as described by Stites et al. (27) using 1.6 $\mathrm{ng}$ and $400 \mathrm{pg}$ of DNA for nuclear and mitochondrial DNA quantification, respectively. The fold changes

relative to controls were calculated using the equation: $2{ }^{-}{ }_{\Delta \Delta} \mathrm{Ct}$ (mitochondria/nuclear) where $\Delta \Delta \mathrm{Ct}$ (mitochondria/nuclear) $=$ mean $\Delta \mathrm{Ct}$ (mitochondria/nuclear) of the control animals - mean $\Delta \mathrm{Ct}$ (mitochondria/nuclear) of the $\operatorname{Tg}(P A N K 2)$ animals.

\subsection{Pantothenate kinase and catalase activity assays}

Tissues were quickly harvested, flash frozen in liquid nitrogen and stored at $-80{ }^{\circ} \mathrm{C}$ until used. Triceps surae indicates the combined gastrocnemius, soleus and plantaris muscles. The total PanK activity was determined in tissue extracts as described previously $(13,15)$. Briefly, frozen tissue $(\sim 100 \mathrm{mg})$ was homogenized in cold hypotonic buffer $\left(20 \mathrm{mM} \mathrm{K}_{2} \mathrm{HPO}_{4}, 1 \mathrm{mM}\right.$ ATP, $\mathrm{pH}$ 7.4) using a Dounce tissue grinder. The homogenates were centrifuged at $20,000 \times \mathrm{g}, 4^{\circ} \mathrm{C}$ for $45 \mathrm{~min}$, and the supernatants were dialyzed overnight in the homogenization buffer. PanK activity was assayed in reaction mixtures containing $100 \mathrm{mM}$ Tris- $\mathrm{HCl}, \mathrm{pH} 7.4,10 \mathrm{mM} \mathrm{MgCl}, 2.5$ mM ATP, $45 \mu \mathrm{M}$ D-[1- ${ }^{14} \mathrm{C}$ ]pantothenate (specific activity, $27.5 \mathrm{mCi} / \mathrm{mmol}$ ), 0-400 $\mu \mathrm{g}$ of homogenate protein depending on the PanK activity of the tissue. Samples were incubated at $37^{\circ} \mathrm{C}$ for $30 \mathrm{~min}$, after which time the reactions were stopped and the amount of phospho $\left[{ }^{14} \mathrm{C}\right]$ pantothenate formed was analyzed as previously described (6). The protein concentrations of the dialyzed samples were determined by the Bradford assay (28), and the total PanK specific activity was determined from the slope of a linear fit to a 5 point protein curve in duplicate (pmoles/min/mg). To determine catalase activity, heart and skeletal muscle tissue (100 mg) was homogenized, diluted 5-50 fold and assayed by the ferrous oxidation method (29).

\subsection{Tissue CoA, Acetyl-CoA, ATP and TBARS measurements}

The amount of CoA in liver was measured as previously described (13). The amount of total CoA in skeletal muscle and heart was determined by derivatization with monobromobimane $(\mathrm{mBBr})$, as previously described (4). For the quantification of acetyl-CoA in heart and hamstring muscle by mass spectrometry, tissue samples were extracted following the addition of $\left[{ }^{13} \mathrm{C}\right]$ acetyl-CoA standard (Sigma) (200 pmol for hamstring muscle; 400 pmol for heart) and cleaned up as we previously described (4). The dried samples were resuspended in $90 \%$ methanol, $15 \mathrm{mM}$ ammonium hydroxide $(200 \mu \mathrm{l})$ and analyzed using a Shimadzu Prominence UFLC LC system attached to a QTrap 4500 mass spectrometer equipped with a Turbo V ion source (Sciex). The samples were loaded using a flow rate of $0.1 \mathrm{ml} / \mathrm{min}$ onto an Acquity UPLC HSS T3, 1.8uM, $2.1 \times 150 \mathrm{~mm}$ column (Waters), previously equilibrated with $95 \%$ solvent $\mathrm{A}$ (10 mM ammonium acetate $\mathrm{pH} 6.8$ ), $5 \%$ solvent $\mathrm{B}$ $(95 \%$ acetonitrile, $10 \mathrm{mM}$ ammonium acetate $\mathrm{pH} 6.8)$ at $40{ }^{\circ} \mathrm{C}$. The column was washed with $95 \% \mathrm{~A} / 5 \% \mathrm{~B}, 0$ 
to 2 min and sample elution was performed using a 2 to 20 min linear gradient up to $100 \%$ B followed by 20 to $25 \min 100 \%$ B. The QTrap 4500 was operated in the positive mode, and the ion source parameters were: ion spray voltage, $5500 \mathrm{~V}$; curtain gas, 15 psi; temperature, $400{ }^{\circ} \mathrm{C}$; collision gas, medium; ion source gas 1 , 15 psi, and ion source gas 2, 20 psi. The MRM transition for acetyl-CoA was $810.1 / 303.1 \mathrm{~m} / \mathrm{z}$ with a declustering potential, $60 \mathrm{~V}$ and collision energy, $35 \mathrm{~V}$. The system was controlled by the Analyst ${ }^{\circledR}$ software $^{2}$ (Sciex) and tissue acetyl-CoA peak area was quantified relative to $\left[{ }^{13} \mathrm{C}\right.$ ]acetyl-CoA using MultiQuant ${ }^{\mathrm{TM}}$ 3.0.2 software (Sciex).

To measure ATP, tissue samples were homogenized in 5\% trichloroacetic acid and centrifuged at 14,000 rpm

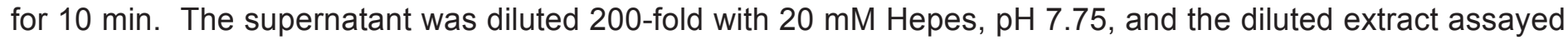
for ATP using the Enliten ATP Assay Kit (Promega), as per manufacturer's instructions. An ATP calibration curve was obtained to convert the luminescence signal into nmoles of ATP. For the measurement of thiobarbituric acid reactive species (TBARS) in heart and skeletal muscles, tissue (50 $\mathrm{mg})$ was homogenized in $1 \% \mathrm{KCl}$ and assayed as described (30).

\subsection{Histology and electron microscopy}

Necropsy, tissue fixation, preparation of paraffin sections and hematoxylin and eosin staining were performed by the St. Jude Veterinary Pathology Core facility. For analysis by electron microscopy, the animals were perfused with $2.5 \%$ glutaraldehyde/ $2 \%$ paraformaldehyde in $0.1 \mathrm{M}$ sodium cacodylate buffer, $\mathrm{pH} 7.4$ and submitted to the St. Jude CTI-EM shared resource. Skeletal muscles and hearts were first fixed in the perfusion fixative, and then post fixed in $2 \%$ osmium tetroxide in $0.1 \mathrm{M}$ sodium cacodylate buffer containing $0.3 \%$ potassium ferrocyanide for 1.5 hours. The tissue was rinsed in the same buffer, stained en bloc with aqueous 4\% uranyl acetate, dehydrated through a series of graded ethanol concentrations to propylene oxide, infiltrated and embedded in epoxy resin and polymerized at $70^{\circ} \mathrm{C}$ overnight. Semithin sections (0.5 micron) were stained with toluidine blue for light microscope examination. Ultrathin sections (80 $\mathrm{nm}$ ) were cut and imaged using a FEI FEG Tecnai Electron Microscope with an AMT XR 50 camera.

\subsection{Forced treadmill activity and grip strength performance}

Mice were exercised on a motorized treadmill (Columbus Instruments) equipped with an electrical stimulus and with adjustable belt speed and inclination. $\operatorname{Tg}(P A N K 2)$ and control mice were acclimated to the treadmill environment and belt movement daily for four days prior to the test. The acclimation routine consisted of exercising the mice at low intensity for $10 \mathrm{~min}$ at $12.5 \mathrm{~m} / \mathrm{min}$ and $0^{\circ}$ incline. On the fifth day, the test was conducted by exercising the mice at a speed of $12 \mathrm{~m} / \mathrm{min}$, fixed $15^{\circ}$ incline for $3 \mathrm{~min}$. The speed was then increased to $15 \mathrm{~m} / \mathrm{min}$ and monitoring continued until exhaustion. Exhaustion was defined as spending >10 sec on the electrical stimulus. Forelimb grip strength was measured using a grip strength meter (Ugo Basile). Each mouse was tested once a day for 3 days. The average force from individual mice was used to calculate the mean and the standard error for each genotype. 


\subsection{Mitochondria isolation, blue native gel and activity assays for ATP synthase and complexes of the electron transport chain}

Mitochondria were isolated from fresh hamstring and heart muscles according to the procedure described by Frezza et al (31) with minor modifications that included 1) a wash step with phosphate buffered saline containing $10 \mathrm{mM}$ EDTA after digestion of the tissue with trypsin, 2) the omission of bovine serum albumin from the homogenization buffer and 3) the addition of both protease and deacetylase inhibitors to the homogenization and mitochondria resuspension buffers.

To assess the abundance of ETC complexes I and III, blue native polyacrylamide gel electrophoresis (BNPAGE) was performed as previously described (32), with modifications according to the manufacturer's protocol (Thermo Scientific). Briefly, isolated mitochondria were solubilized with $1 \%$ digitonin and, after the addition of Coomassie G-250, samples were run on 4-16\% NativePAGE gels. Following BN-PAGE, gels were rinsed and stained with GelCode Blue Stain Reagent (Thermo Scientific). The intensity of the bands was estimated by densitometry using ImageJ software. ETC complexes I, III and IV activities were measured spectrophotometrically as previously described (33-36). Briefly, complex I activity was determined by measuring NADH oxidation at $340 \mathrm{~nm}$, complex III activity by measuring the reduction of cytochrome $c$ at 550 $\mathrm{nm}$ in the presence of $50 \mu \mathrm{M}$ of reduced decylubiquinone, and complex IV activity by measuring cytochrome $c$ oxidation at $550 \mathrm{~nm}$. ATP synthase activity was measured as oligomycin-sensitive ATPase activity using an assay coupled with pyruvate kinase, which converts ADP to ATP and produces pyruvate from phosphoenolpyruvate as described previously (36-39). Values for complex activities were expressed as nanomoles substrate converted/min/mg of protein.

\subsection{Statistical Analysis}

Data analysis was conducted using GraphPad Prism software. Results are expressed as means \pm standard error, and significance was determined using the two-tailed Student's t-test. Differences were considered significant if $p<0.05$.

\section{Results and Discussion}

\subsection{Derivation and features of $\mathrm{Tg}(P A N K 2)$ mice}

We generated a strain of transgenic mice that expressed human PANK2 driven by the hybrid cytomegalovirus early enhancer/chicken $\beta$-actin/rabbit $\beta$-globin (CAG) promoter (Fig. $1 A$ ) following pronuclear injection of a linearized expression plasmid into FVB/N fertilized ova, implantation of the ova in foster dams and genetic screening of progeny (Fig. 1B). The $\operatorname{Tg}(P A N K 2)$ mice were maintained as a hemizygous line by breeding with C57BL/6J mice for $>6$ generations, and littermates lacking the transgene were used as the control animals. Breeding of hemizygous males with hemizygous females produced viable offspring, including homozygous 
mice; however, loss of pups of random genotype during the period between birth and weaning was consistently observed, possibly due to poor parenting.

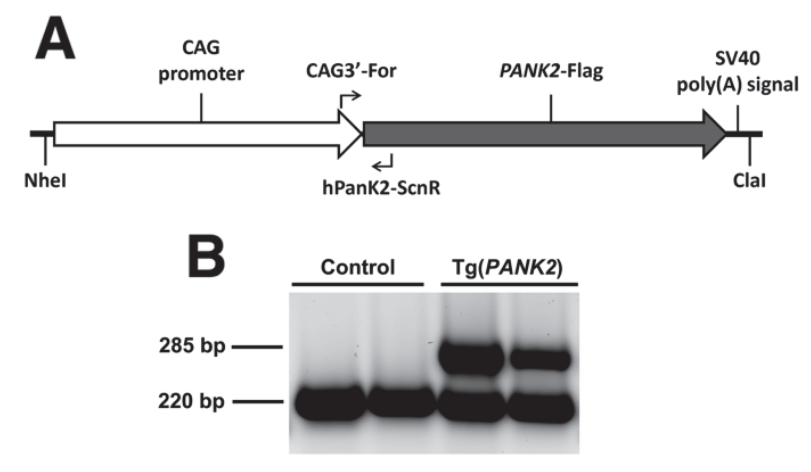

Figure 1. Generation of the $\mathrm{Tg}(P A N K 2)$ mice.

(A) Schematic representation of the construct utilized to generate the $\operatorname{Tg}(P A N K 2)$ mice. Human PANK2 expression was driven by the hybrid CMV early enhancer/chicken $\beta$-actin/rabbit $\beta$-globin (CAG) promoter fused to the PANK2 cDNA. CAG3'-For and hPanK2-ScnR indicate the positions of the primers used for genotyping. $(B)$ Representative genotyping of the mice. Multiplex PCR reactions were used to detect the transgene as a 285-bp product and an unrelated control gene with a product of $220 \mathrm{bp}$ (see "Experimental Procedures").

Next generation sequencing was used to identify the insertion site(s) of the transgene in the $\operatorname{Tg}(P A N K 2)$ mice. The transgene was inserted in two sites, confirmed by PCR amplification and Sanger sequencing, found approximately $53 \mathrm{~kb}$ apart within the same genomic region, on chromosome 14 2qF1 (Fig. S1). Specifically, one insertion point was in a long terminal repeat at chr14:100,874,633 (GRCm38 assembly). This site contained at least one full length copy of the PANK2 coding sequence and two truncated copies (Fig. S1). The second insertion point was at chr14:100,821,780 and contained a fragment of the $5^{\prime}$ end of the PANK2 construct. Importantly, the genomic region that flanked the two insertion sites did not contain annotated genes, ruling out the possibility that the random insertion of the transgene construct might have disrupted a coding sequence. Indeed, the nearest annotated gene, Prr30, which has no currently known function, was located over $320 \mathrm{~kb}$ downstream of the two transgene insertions. Furthermore, although the depth of the sequencing was too shallow to accurately determine the copy number of the transgene, the similarity between the 6.8 fold coverage of the construct sequence obtained by mapped reads and the 4.1 fold coverage of the mouse genome obtained by the mapped reads from our library suggests that the PANK2 construct was not inserted at a high copy number in the $\operatorname{Tg}(P A N K 2)$ mouse line.

$\operatorname{Tg}(P A N K 2)$ mice were born at the expected Mendelian ratio but they were significantly smaller than littermate controls. Both male and female transgenic mice remained smaller into adulthood, with weights approximately $25 \%$ lower at 16 weeks of age (Fig. $2 A$ and $B$ ). The $\operatorname{Tg}(P A N K 2)$ mice were also shorter in body length (Fig. $2 C$ ) and had a lower body-mass index (Fig. 2D). The small body phenotype of the $\operatorname{Tg}(P A N K 2)$ mice was due at least in part to a $20 \%$ lower daily food intake (Fig. 2E). Both male and female $\operatorname{Tg}(P A N K 2)$ mice exhibited the same phenotype and so the analysis was focused on males. The organ weights normalized to body weight of the $\operatorname{Tg}(P A N K 2)$ mice were compared to littermates to determine if there was a selective impairment in the 
development of individual organs (Fig. $2 F$ ). The skeletal muscles of the transgenic mice were all significantly smaller compared to control mice. No difference was observed in white adipose tissue, while the liver, kidneys, heart, brown adipose tissue and brain all contributed slightly more to body weight in the $\operatorname{Tg}(P A N K 2)$ mice. These data suggested that skeletal muscle mass was selectively reduced in the $\operatorname{Tg}(P A N K 2)$ mice.
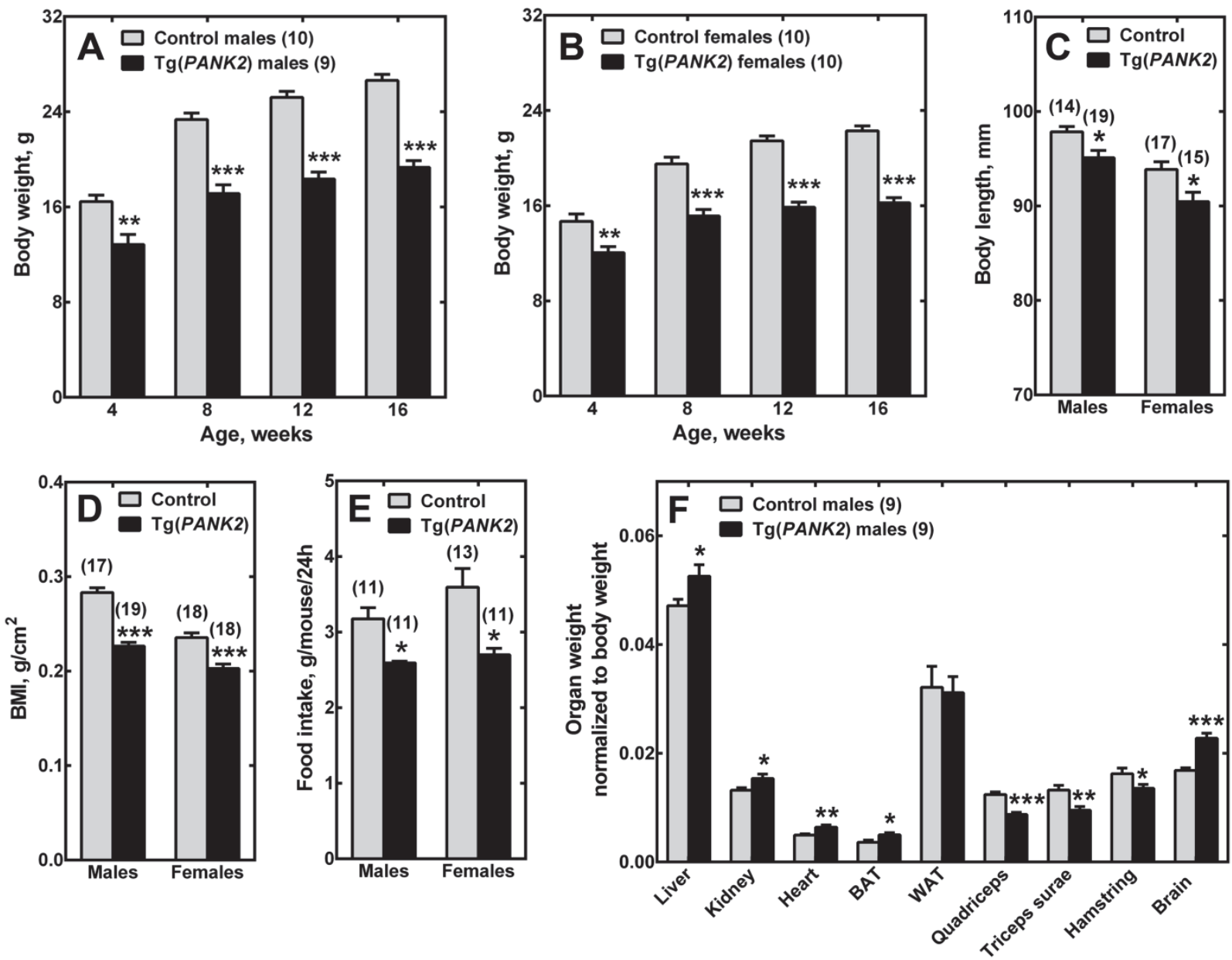

Figure 2. General features of the $\operatorname{Tg}(P A N K 2)$ mice.

Weight gain of $(A)$ male and $(B)$ female control and $\operatorname{Tg}(P A N K 2)$ mice with age. (C) Body length and $(D)$ body mass index (BMI) of age-matched $\mathrm{Tg}(P A N K 2)$ and control mice. (E) Food intake by control and $\mathrm{Tg}(P A N K 2)$ mice. Mice were housed 3-5 per cage (3 cages/gender/genotype) and food consumption monitored every $24 \mathrm{~h}$ over 4 days. $(F)$ Organ weights normalized to body weights in control and $\operatorname{Tg}(P A N K 2)$ mice. Abbreviations: BAT, brown adipose tissue; WAT, white adipose tissue. The number of mice is indicated in parentheses, and the plotted data represent the mean \pm the standard error. The Student's t-test was used to determine significance: ${ }^{*}, p<0.05 ;{ }^{* *}, p<0.01 ;{ }^{* * *}, p<0.001$.

Analysis of serum samples from $\operatorname{Tg}(P A N K 2)$ and control mice did not reveal any significant abnormalities in multiple parameters measuring liver and kidney function (Table 1). Glucose and insulin levels were lower in the $\operatorname{Tg}(P A N K 2)$ mice sampled in the fed state compared to their wild-type counterparts, possibly related to their lower food intake. However, no differences in blood glucose and insulin were detected between genotypes in the fasted state, and $\operatorname{Tg}(P A N K 2)$ and control mice showed a similar response to a glucose tolerance test (Fig. 
S2). Analysis of whole body fuel metabolism using indirect calorimetry under ad libitum feeding, fasting and refeeding conditions did not reveal any significant differences in the volumes of oxygen consumed $\left(\mathrm{VO}_{2}\right)$ and carbon dioxide $\left(\mathrm{VCO}_{2}\right)$ produced between genotypes when corrected for body size (Fig. S3B-C). The $\mathrm{VCO}_{2} / \mathrm{VO}_{2}$, or respiratory exchange ratio (RER) is an indicator of the type of fuel being used for energy production by the animal, with 1.0 representing exclusively carbohydrate oxidation and a ratio of 0.7 representing primarily fatty acid oxidation. The RER was similar between control and $\operatorname{Tg}(P A N K 2)$ mice during the ad libitum feeding and the fasting periods of the study, with only a slight elevation for the $\operatorname{Tg}(P A N K 2)$ mice during the re-feeding period (Fig. S2A). These data indicated that, while affecting body weight and muscle mass, PANK2 overexpression did not cause significant changes in whole body carbohydrate and lipid metabolism under ad libitum fed or fasted conditions.

\subsection{PANK2 is selectively expressed in muscle tissues of the $\operatorname{Tg}(P A N K 2)$ mice}

The levels of PANK2 mRNA were determined in $\mathrm{Tg}(P A N K 2)$ mouse tissues (Fig. $3 A)$. The transgene mRNA was not expressed at the same levels in all tissues. Liver, brain, and kidney all had low but detectable PANK2 expression; however, the levels of PANK2 mRNA were 5-8-fold higher in muscle tissues such as hearts, hamstrings, quadriceps and triceps surae. Immunoblotting tissue extracts determined the levels of PANK2 protein using an antibody that reacted specifically with human PANK2, and not mouse PanK2 (22). Hearts and skeletal muscles expressed high levels of PANK2 whereas liver, kidney and brain did not exhibit robust PANK2 expression (Fig. 3B). Longer exposures and/or higher protein loading of the gels revealed that PANK2 was expressed in these tissues, but at much lower levels compared to muscle. The tissue expression pattern for the $\operatorname{Tg}(P A N K 2)$ mice was very similar to that reported in transgenic rodents with green fluorescent protein or human ATP7A expression driven by the CAG promoter (40-42).

The primary PANK2 translation product has a molecular weight of $63 \mathrm{kDa}$, and is processed by two consecutive proteolytic steps inside the mitochondria to the $48 \mathrm{kDa}$ form that is located in the mitochondrial intermembrane space $(22,43)$. Overexpression of PANK2 in HEK-293T cells overwhelmed this processing and both the unprocessed primary translation product plus the mitochondrial form were detected (Fig. 3B). Comparison of the PANK2 proteins from $\mathrm{Tg}(P A N K 2)$ heart and skeletal muscles with PANK2 overexpression in HEK-293T cells showed that the majority of the PANK2 transgene product was correctly processed to the mature mitochondrial form (Fig. 3B). Note that the relative amount of GAPDH protein per $50 \mu \mathrm{g}$ of tissue homogenate differed between heart and skeletal muscles in the last panel of Fig. $3 \mathrm{~B}$, and so the degree of PANK2 overexpression was best indicated by the activity data in Table 2. 

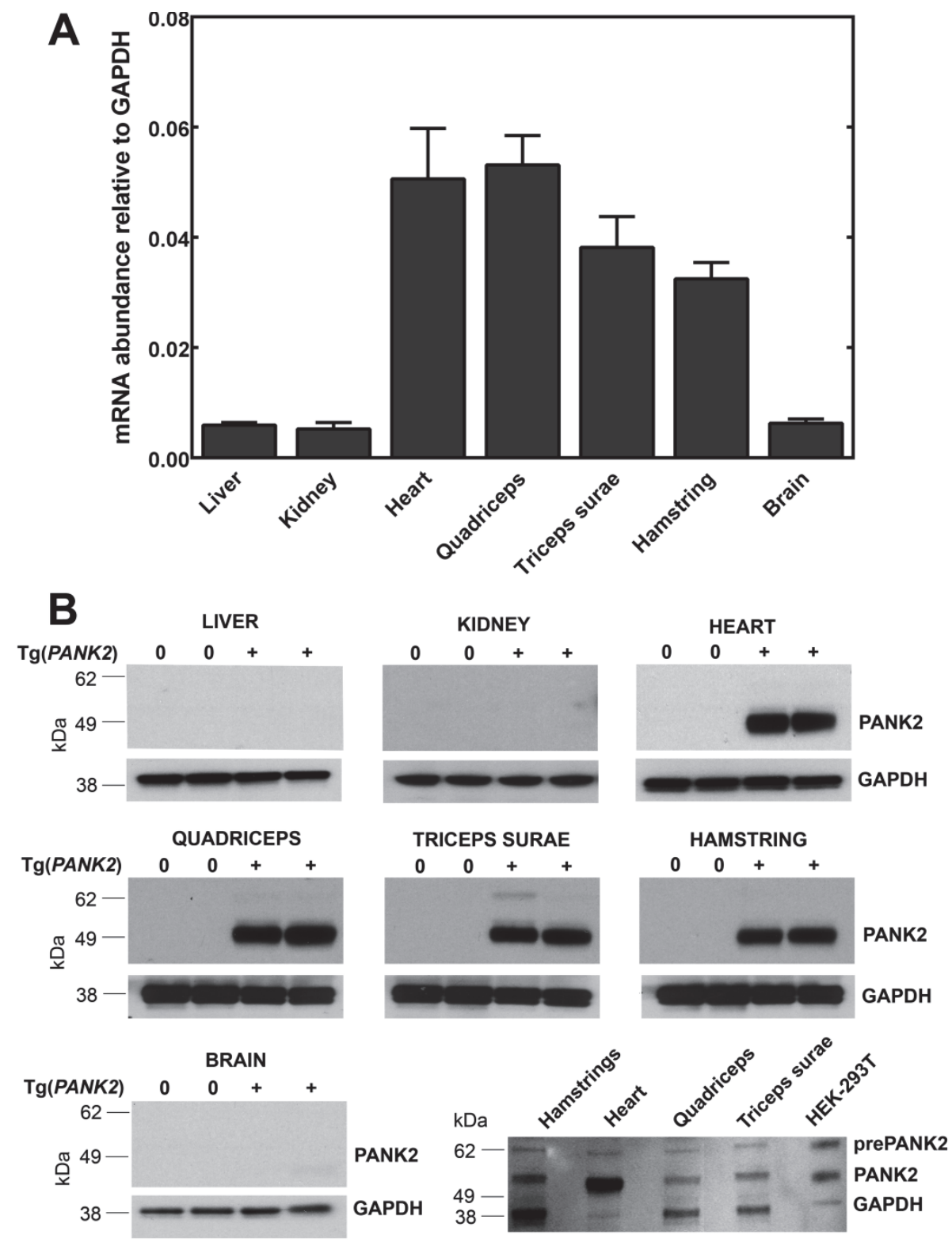

Figure 3. PANK2 mRNA and PANK2 protein expression levels in tissues of $\mathrm{Tg}(P A N K 2)$ mice

(A) PANK2 mRNA levels were quantified by RT-qPCR using a primer set that did not detect mouse Pank2 mRNA. (B) Immunoblot analyses to determine PANK2 protein levels in tissues. Tissues were collected from two representative control $(0)$ and $\operatorname{Tg}(P A N K 2)(+)$ mice and the levels of PANK2 protein were compared by SDS-PAGE fractionation and immunoblotting $50 \mu \mathrm{g}$ tissue lysate protein with PANK2-specific antisera. GAPDH was used as a loading control. The bottom right panel compares PANK2 expressed in different muscle tissues of the $\mathrm{Tg}($ PANK2) mice (50 $\mathrm{\mu g}$ of tissue homogenate protein) to PANK2 expressed in HEK-293T cells $(2 \mu \mathrm{g}$ cell lysate protein). The slower migrating band observed in the HEK-293T cells corresponded to the $63 \mathrm{kDa}$ un-processed primary translation product that accumulated when PANK2 was highly overexpressed in this system. The band at $48 \mathrm{kDa}$ in the muscles and HEK-293T cells corresponded to the mature, mitochondrial PANK2.

Crude tissue homogenates, cleared of insoluble material, were prepared and the total PanK specific activity was determined in tissues from transgenic and control mice (Table 2). PanK activity was higher in all 
transgenic tissues examined, although there were significant differences among the magnitudes of the increases. In control animals, liver and brain had the highest basal levels of PanK activity, while heart and skeletal muscles had lower PanK activities in vitro. The total PanK activity is a function of the Pank gene expression profile, which is different for each tissue. Furthermore, the total PanK activity and the CoA levels in a given tissue correlate with the relative abundance of Pank1 transcripts compared to the other Pank isoforms (44). Consistent with the correlation, Pank1 is a minor isoform in skeletal muscle while it is the major isoform in the heart, thus explaining the differences in the measured basal activities in these tissues from control animals. The organs with the largest increase in PanK activity in the $\operatorname{Tg}(P A N K 2)$ mice were the heart and skeletal muscles, consistent with the high PANK2 protein overexpression as seen with immunoblotting (Fig. 3). For example, there was a 2-fold increase in total PanK activity in brain, whereas there was over a 100-fold increase in PanK activity in the heart and in all skeletal muscle groups that were examined, e.g., the hamstrings, quadriceps and triceps surae. These data support the conclusion that PANK2 protein was expressed at the highest levels in the heart, followed by skeletal muscle. The results indicated a muscleselective expression of the transgene in the $\operatorname{Tg}(P A N K 2)$ mouse strain, which translated into a substantial increase in PANK2 protein and PanK activity in lysates from these tissues.

\subsection{CoA levels and altered mitochondrial morphology in the muscles of the $\mathrm{Tg}(P A N K 2)$ mice}

The impact of transgene expression on tissue CoA levels was determined. In the livers, brains and hearts there were no changes in the concentration of this cofactor (Fig. 4A, 4B and $4 C$ ). Conversely, CoA levels were substantially increased in the skeletal muscles from the $\mathrm{Tg}(P A N K 2)$ mice (Fig. $4 D$ and $4 E$ ). PANK2 is the most stringently feedback regulated of all the isoforms (45), and high levels of tissue acetyl-CoA would function to inhibit the PanK activity in the order PANK2=PanK2>PanK3>PanK1. Although PANK2 was highly expressed in the heart, the transgene was unable to elevate CoA levels above the concentration found in control hearts. One explanation for this result could be the relatively high basal concentration of acetyl-CoA that was found in heart muscle (Fig. 4F). Acetyl-CoA binding to the human PANK and mouse PanK enzymes is highly cooperative (46), meaning that the degree of inhibition increases exponentially as a function of the acetyl-CoA concentration. These data did not rule out CoA turnover as a contributing mechanism to maintain cardiac CoA homeostasis, although nudix hydrolase expression is relatively low, if any, in the heart. In contrast, acetyl-CoA levels in control hamstring muscles were about 7 times lower than in control hearts (Fig. 4F), suggesting that the skeletal muscle-specific increase in total CoA levels following overexpression of PANK2 was possibly associated with less feedback inhibition of the PanK activity compared to heart. Interestingly, despite the notably higher total $\mathrm{CoA}$ content, hamstring muscles from $\operatorname{Tg}(P A N K 2)$ mice contained the same amount of acetyl-CoA as control mice, indicating the existence of mechanisms to prevent acetyl-CoA buildup. One such mechanism could be the transfer of acetyl groups from acetyl-CoA to carnitine catalyzed by carnitine acetyltransferase, an enzyme that is highly abundant in skeletal muscle and heart $(47,48)$, and whose activity is important to buffer the acetyl-CoA pool (49-51). 

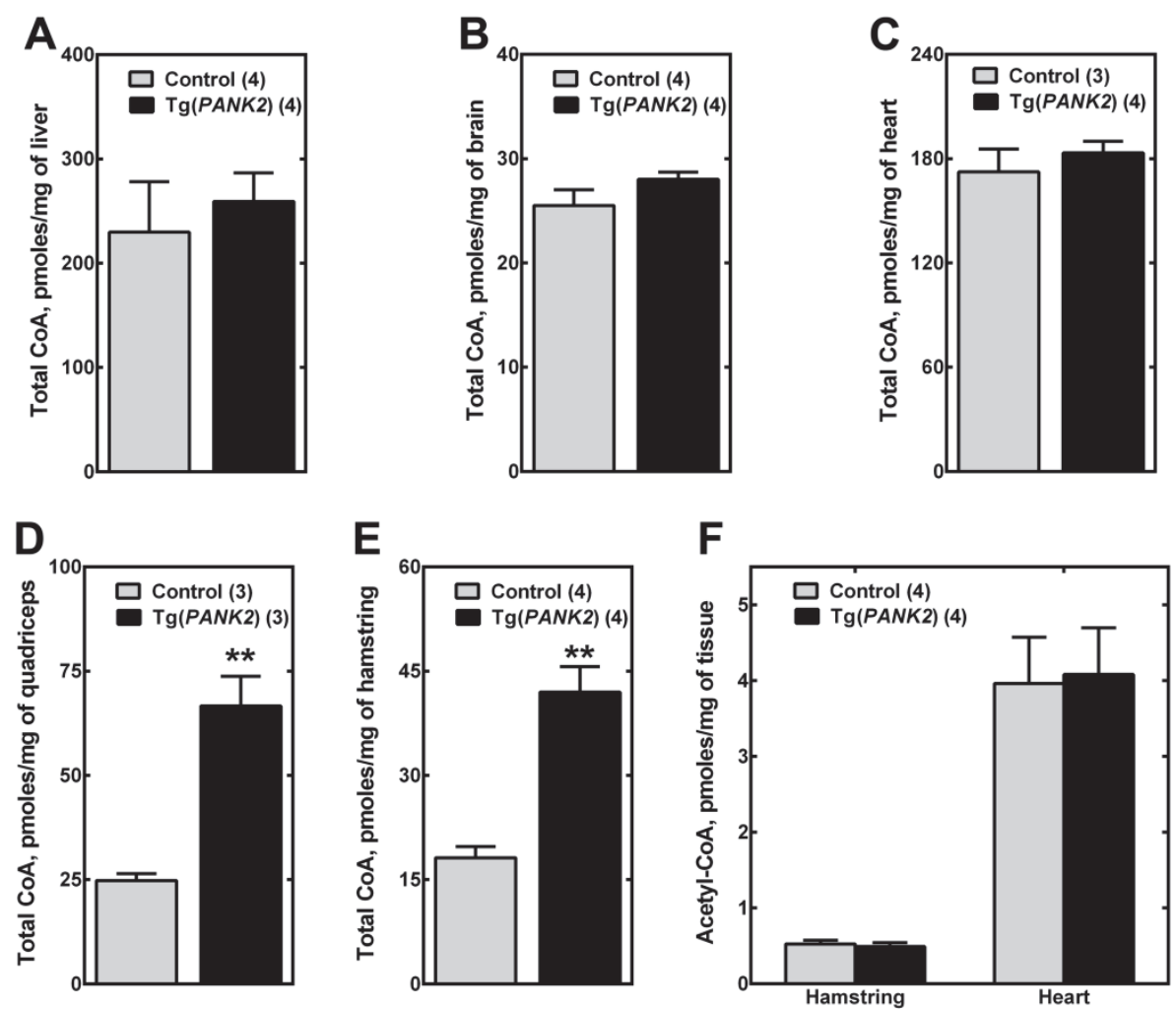

Figure 4. CoA levels in selected tissues from control and $\operatorname{Tg}(P A N K 2)$ mice

Total CoA levels measured in $(A)$ liver, $(B)$ brain, $(C)$ heart, $(D)$ quadriceps, and $(E)$ hamstring muscles of $\mathrm{Tg}($ PANK2) and control animals. ( $F)$ Acetyl-CoA content of hamstring and heart muscles in $\mathrm{Tg}(P A N K 2)$ and control animals measured by mass spectrometry as described in the "Experimental Procedures" section. The number of mice/genotype used for each experiment is indicated in parentheses, and the plotted data represent the mean \pm the standard error. Student's t-test was used to determine significance: ${ }^{* *}, p<0.01 ;{ }^{* * *}, p<0.001$.

Light microscopy revealed a significant difference between the skeletal muscles of $\operatorname{Tg}(P A N K 2)$ mice and the control mice (Fig. 5). Nuclei in mature skeletal muscles are characteristically located at the myofiber margins (Fig. 5A, control); however, in the $\operatorname{Tg}(P A N K 2)$ mice many muscle fibers exhibited centrally located nuclei (Fig. 5A), characteristic of developing or regenerating muscle fibers. This phenotype was associated with normal serum levels of creatine phosphokinase in the $\operatorname{Tg}(P A N K 2)$ mice (Table 1), indicating the absence of pronounced muscle damage. No morphological differences were observed by light microscopy in the hearts between control and $\operatorname{Tg}(P A N K 2)$ samples (Fig. 5B). Electron microscopic examination revealed normal fiber ultrastructure in the quadriceps of control animals (Fig. $5 C$ ); however, the $\operatorname{Tg}(P A N K 2)$ quadriceps showed irregular striatal patterns and clear disturbance in the mitochondrial zones between the fibers at 5,000x magnification. The mitochondria in the $\operatorname{Tg}(P A N K 2)$ skeletal muscles were not distributed in a regular pattern associated with the striations as found in control muscles, but rather were clustered at fewer sites in greater numbers. It is uncertain whether greater mitochondrial size or the clustering, or both attributes, contributed to the apparent increase in mitochondria in the $\operatorname{Tg}(P A N K 2)$ skeletal muscles. Quantification of mitochondrial 
DNA normalized to nuclear DNA in skeletal muscle showed no significant difference between $\operatorname{Tg}(P A N K 2)$ mice and the control mice (Fig. 6C), indicating that, unlike the local distribution, the total number of mitochondria was not affected by the overexpression of PANK2. Higher magnification $(29,000 x)$ showed that the mitochondria had greater volume in the periphery in the subsarcolemmal area and within fibers. A diffuse loss of architecture within the mitochondria without any clear delineation of cristae characterized the $\operatorname{Tg}(P A N K 2)$ quadriceps, and similar results were observed for hamstring muscles (data not shown). On the other hand, the mitochondria in the $\operatorname{Tg}($ PANK2) heart showed only a partial loss of mitochondrial cristae and a larger volume compared to control heart (Fig. 5D). These data suggested that overexpression of the PANK2 protein disturbed organization within heart mitochondria. However, both overexpression of PANK2 protein and elevated CoA were associated with a more drastic swollen appearance and almost complete absence of mitochondrial cristae in skeletal muscle.

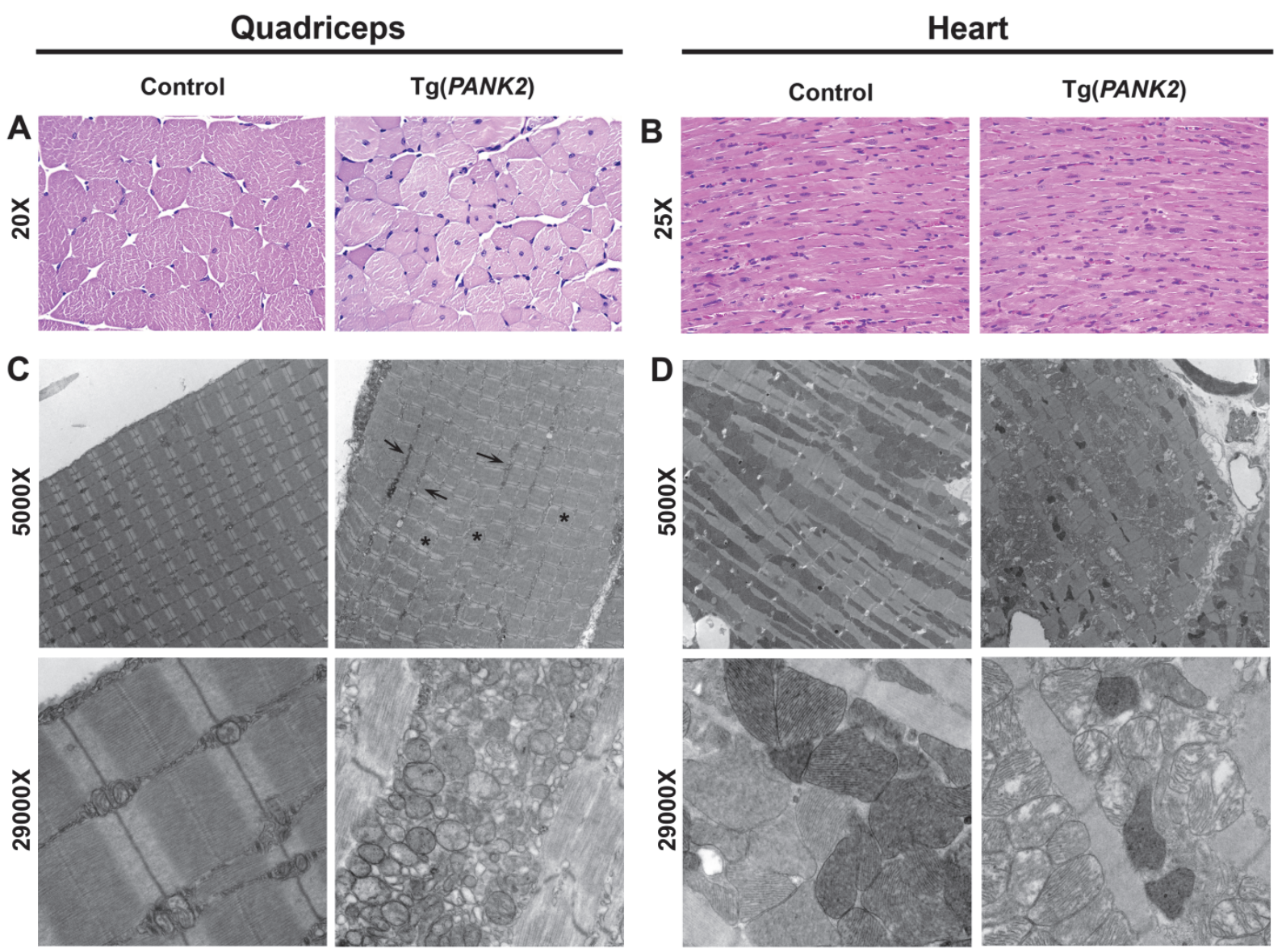

Figure 5. Representative histology and electron microscopy of muscle tissues in Tg(PANK2) and control mice

Hematoxylin and eosin staining of $(A)$ quadriceps muscles and $(B)$ hearts of $\operatorname{Tg}(P A N K 2)$ and control mice showing the presence of centrally located nuclei in the transgenic quadriceps muscles. Similar results were observed for hamstring muscles compared to quadriceps. Mouse tissues were collected and processed for electron microscopy $(C)$ and $(D)$. (C) Uneven distribution of mitochondria in the striations of the $\operatorname{Tg}(P A N K 2)$ quadriceps, with arrows and asterisks pointing to regions of higher and lower mitochondrial density, respectively, compared to control muscles. Note also the swollen mitochondria of the $\operatorname{Tg}(P A N K 2)$ quadriceps 
at higher magnification compared to normal appearance in the controls. $(D)$ Modest changes in the size and morphology of heart mitochondria in the $\mathrm{Tg}(P A N K 2)$ mice compared to control mice. Results shown were typical of 3-5 mice examined.

\subsection{Tg(PANK2) mice exhibit reduced treadmill endurance, decreased ATP and complex I content and} increased signs of oxidative stress in skeletal muscle

The reduced size and aberrant morphology of the hind limb skeletal muscles expressing PANK2 led us to determine if muscle performance was impaired in $\operatorname{Tg}(P A N K 2)$ mice. Treadmill endurance measures skeletal muscle performance and it is also influenced by cardiovascular function. Although the $\operatorname{Tg}(P A N K 2) \mathrm{mice}$ exhibited near normal heart morphology, these animals performed significantly worse in forced treadmill activity, reaching exhaustion in less than half the time of the control animals (Fig. 6A). Furthermore, the $\operatorname{Tg}(P A N K 2)$ mice exhibited reduced forelimb grip strength compared to the control mice (Fig. 6B), indicating a generalized skeletal muscle phenotype resulting from PANK2 overexpression. Having ruled out a significant difference in the total number of skeletal muscle mitochondria between genotypes (Fig. 6C), the deficit in muscle performance suggested reduced mitochondrial functionality. Mitochondria are the site of ATP generation via the electron-transport chain, and the components of the electron-transport chain are localized at the mitochondrial cristae. Skeletal muscles expressing the PANK2 transgene had a significant $20 \%$ reduction in resting ATP levels (Fig. 6D). These data, together with the almost complete absence of mitochondrial cristae organization in $\operatorname{Tg}(P A N K 2)$ skeletal muscle, led us to evaluate the electron transport chain (ETC) and ATP synthase activities.
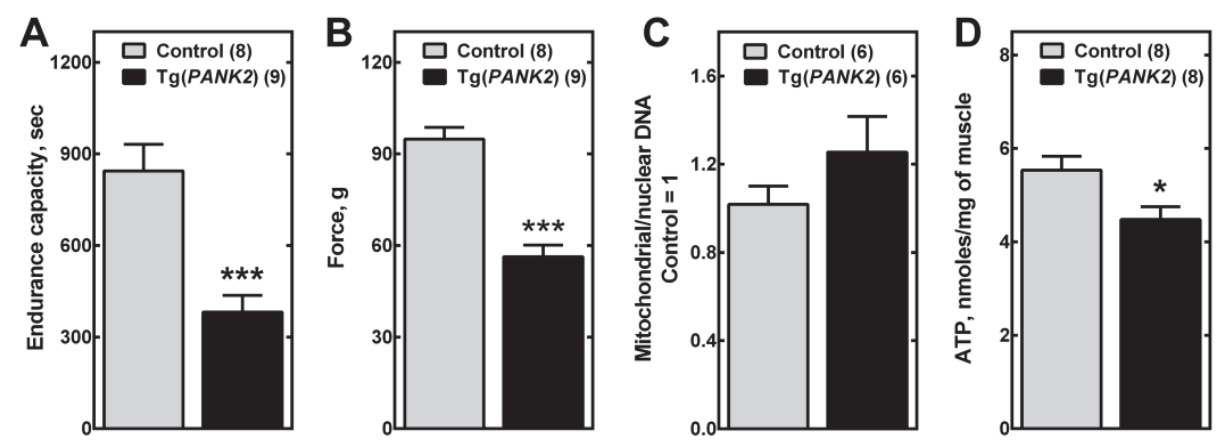

Figure 6. Reduced skeletal muscle endurance capacity, grip strength and ATP content in $\operatorname{Tg}(P A N K 2)$ mice

$\operatorname{Tg}(P A N K 2)$ mice had significantly reduced $(A)$ treadmill endurance and $(B)$ grip strength compared to control mice. $(C)$ The ratio between mitochondrial DNA and nuclear DNA in hamstring muscles was not significantly different between control and $\operatorname{Tg}(P A N K 2)$ mice. (D) The ATP content of hamstring muscles was reduced in $\mathrm{Tg}(P A N K 2)$ mice. The number of mice/genotype used for each experiment is indicated in parentheses, and the plotted data represent the mean \pm the standard error. Student's t-test was used to determine significance: ${ }^{*}, p<0.05 ;{ }^{* *}, p<0.001$.

No differences in ATP synthase activity were noted between mitochondria isolated from transgenic and control skeletal muscle groups (Fig. 7A). However, measurement of the enzymatic activities of ETC complexes I, III 
and IV revealed a significant reduction in the activity of complex I in mitochondria isolated from $\operatorname{Tg}(P A N K 2)$ skeletal muscles, while the specific activities of complex III and IV were comparable between genotypes (Fig. 7A). The selective reduction of complex I activity was associated with a decrease in the levels of fully assembled complex I as determined by blue native gel (Fig 7B), and further confirmed by a reduction in the western blot signal of Ndufa9, one of the subunits of complex I (Fig. 7C). These data indicated that reduced ETC activity due to reduced complex I could account for the decrease in ATP levels in transgenic skeletal muscle.
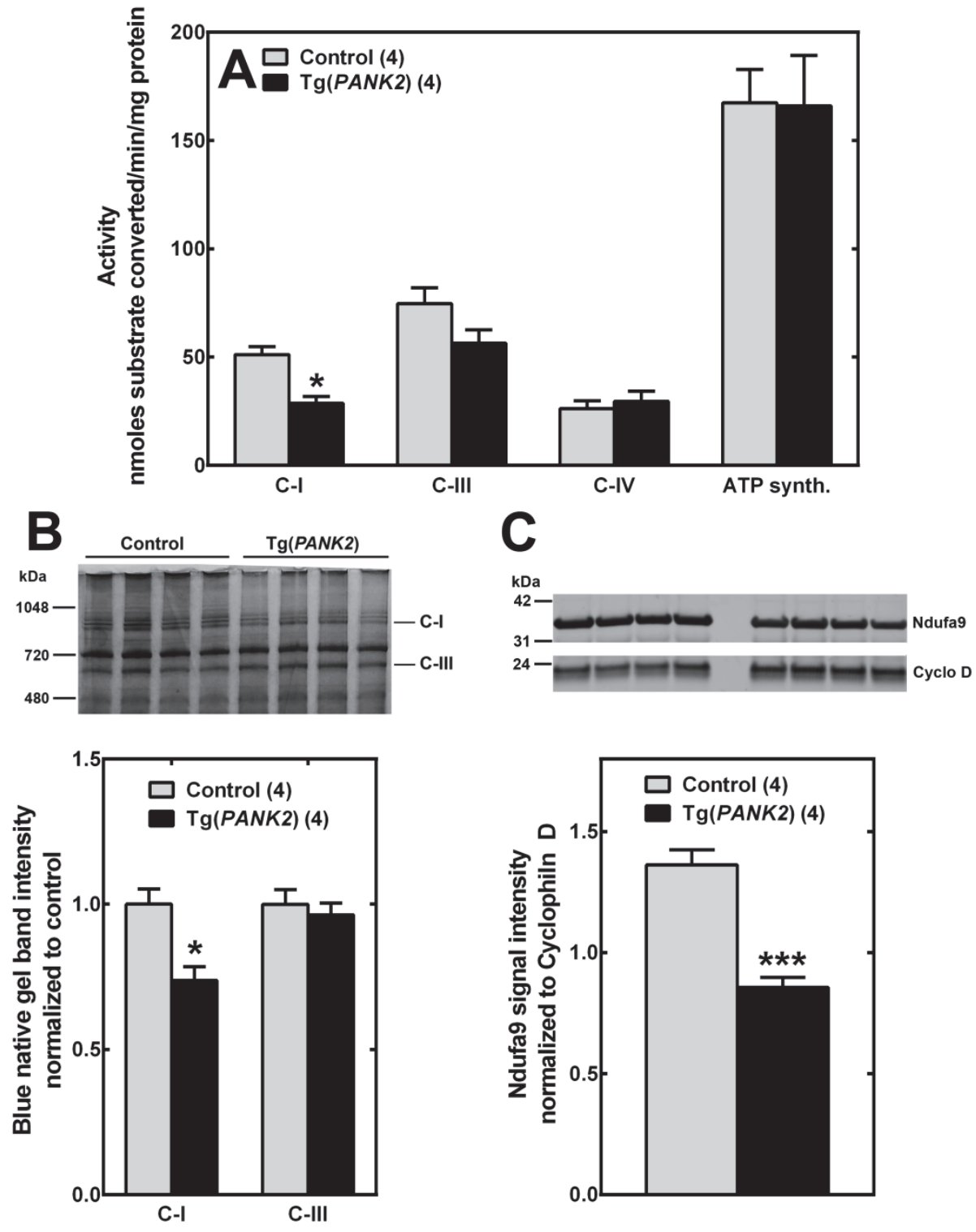

Figure 7. Reduced complex I activity and content in the skeletal muscles of $\mathrm{Tg}(P A N K 2)$ mice

(A) The activity of ATP synthase and of complexes I, III and IV of the electron transport chain were assessed spectrophotometrically by measuring the oxidation of NADH (complex I, C-I and ATP synthase), reduction of cytochrome C (Complex III, C-III) and oxidation of cytochrome C (Complex IV, C-IV), as described in "Experimental Procedures". (B) Analysis of the hamstring muscle content of fully assembled complexes I and 
III by blue native gel and quantification of the band intensity. (C) Western blot analysis of the complex I subunit Ndufa9 in control and $\mathrm{Tg}(P A N K 2)$ hamstring muscle mitochondria and quantification of the signal. Cyclophilin $D$ was used as a loading control. ImageJ and ImageQuant TL 8.1 software were used to analyze the images in panels $B$ and $C$, respectively. The number of mice/genotype used for each experiment is indicated in parentheses, and the plotted data represent the mean \pm the standard error. Student's $t$-test was used to determine significance: ${ }^{*}, p<0.05 ;{ }^{* *}, p<0.001$

We also measured ATP levels, ETC complex activity and abundance in the heart, an organ with robust expression of the transgene but normal CoA levels (Fig. $3 B$ and $4 C$ ). In contrast to the skeletal muscle, no difference in heart ATP levels (Fig. 8A), complex I activity or content was detected in the $\operatorname{Tg}(P A N K 2)$ mice compared to control mice (Fig. $8 B-C$ ). These results corroborated the conclusion that the reduction in exercise performance and ATP levels was linked to the higher CoA concentration in the skeletal muscle of the $\operatorname{Tg}(P A N K 2)$ mice.
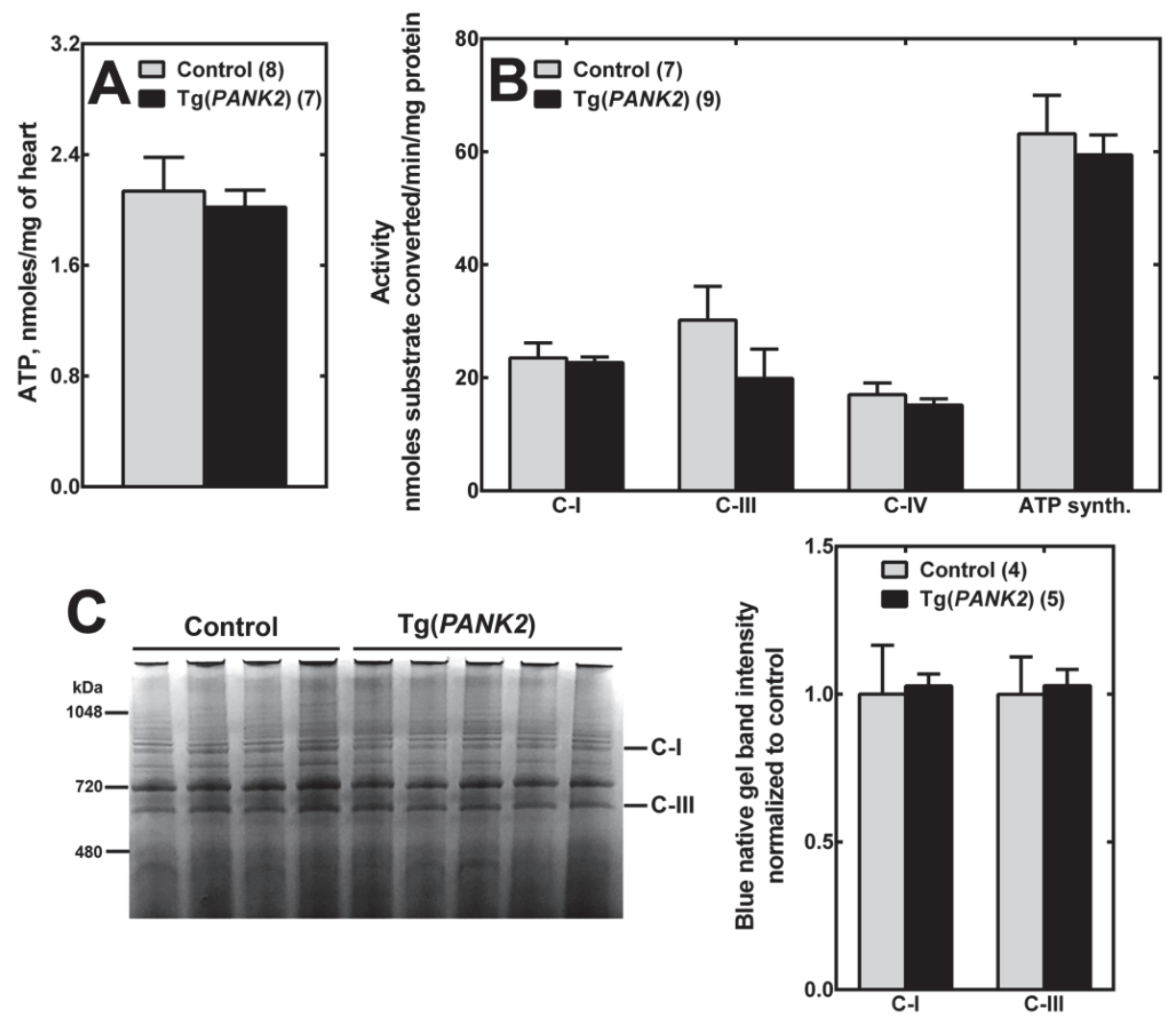

Figure 8. Overexpression of PANK2 does not affect complex I activity or content in the hearts of $\operatorname{Tg}($ PANK2) mice

(A) ATP levels in the hearts of $\operatorname{Tg}(P A N K 2)$ mice were similar to control mice. $(B)$ The activities of ATP synthase and complexes I, III and IV of the electron transport chain, measured spectrophotometrically as described in "Experimental Procedures", were similar between genotypes. (C) Analysis of the fully assembled complexes I and III by blue native gel and quantification of the band intensity in $\operatorname{Tg}(P A N K 2)$ and control hearts using Image $\mathrm{J}$ software. The number of mice/genotype used for each experiment is indicated in parentheses, and the plotted data represent the mean \pm the standard error. Student's t-test was used to determine significance. 
Dysfunction of the ETC, including reduced assembly of complex $\mathrm{I}$, is often associated with increased generation of reactive oxygen species (ROS) and oxidative stress $(52,53)$. Oxidative conditions, in turn, can further compromise complex I stability and assembly (54). Therefore, we analyzed the skeletal muscle of $\operatorname{Tg}(P A N K 2)$ and control mice for signs of oxidative stress, using the heart as a negative control (Fig. 9). Thiobarbituric acid reactive substances (TBARS) provide an indirect measure of ROS levels and measure malondialdehyde as well as other metabolites related to lipid peroxidation. The TBARS levels in control and $\mathrm{Tg}$ (PANK2) mice showed that transgene expression was associated with an increase in TBARS in skeletal muscle, but not in heart (Fig. 9A). The cellular responses to oxidative stress involve the initiation of a distinct transcriptional program to adapt to the stress (55). The activated expression profile includes target genes such as superoxide dismutase (Sod1, Sod2), glutathione reductase (Gpx1), catalase (Cat) and Gadd45a, a marker for environmental stress and a critical stress-induced mediator of muscle atrophy (56). The expression of several of these genes was significantly upregulated in the hamstring muscles of $\operatorname{Tg}(P A N K 2)$ mice (Fig. 9B), while only Gadd45a and Gpx1 were modestly increased in the hearts (Fig. 9C). This transcriptional response suggested that the skeletal muscle in $\mathrm{Tg}(P A N K 2)$ animals experienced more oxidative stress. The induction of catalase expression resulted in a robust increase in catalase enzymatic activity in hamstring muscles from $\operatorname{Tg}(P A N K 2)$ mice (Fig. 9D). Conversely, overexpression of PANK2 did not stimulate catalase activity in the hearts.

Taken together, the above results indicated that the higher oxidative stress and the observed reduction in ATP levels in $\operatorname{Tg}(P A N K 2)$ skeletal muscles were likely associated with the $\sim 40 \%$ decrease in the activity of complex I. The decreased availability of ATP for muscle contraction and the smaller muscle mass, in turn, likely accounted for the significant reduction in exercise performance and grip strength that characterized the $\operatorname{Tg}(P A N K 2)$ mice (Fig. $6 A$ and $B)$.

The phenotype of the $\operatorname{Tg}(P A N K 2)$ mice reveals a connection between $\mathrm{CoA}$ levels and the activity and stability of complex I. Mammalian complex I is a large enzyme comprised of 45 different subunits that are encoded by both the nuclear and mitochondrial DNA and that need to be correctly assembled to form a functional mature holoenzyme (57). The assembly of complex I requires a number of distinct assembly factors, and genetic mutations in either complex I subunits or assembly factors result in reduced complex I content and activity (58). Changes in the composition and concentration of the CoA/acyl-CoA pool could affect the activity, assembly and/or stability of complex I by different potential mechanisms, including allosteric inhibition or changes in the acylation state of one or multiple subunits and/or assembly factors. Indeed, several of the subunits in complex I are known to be posttranslationally modified with acetyl and myristoyl groups (59), and one of the subunits is an acyl-carrier protein that derives its (acyl)phosphopantetheine prosthetic group from CoA (60). Further work will be required to determine the specific mechanism(s) through which elevated CoA decreases complex I stability in skeletal muscle mitochondria. 

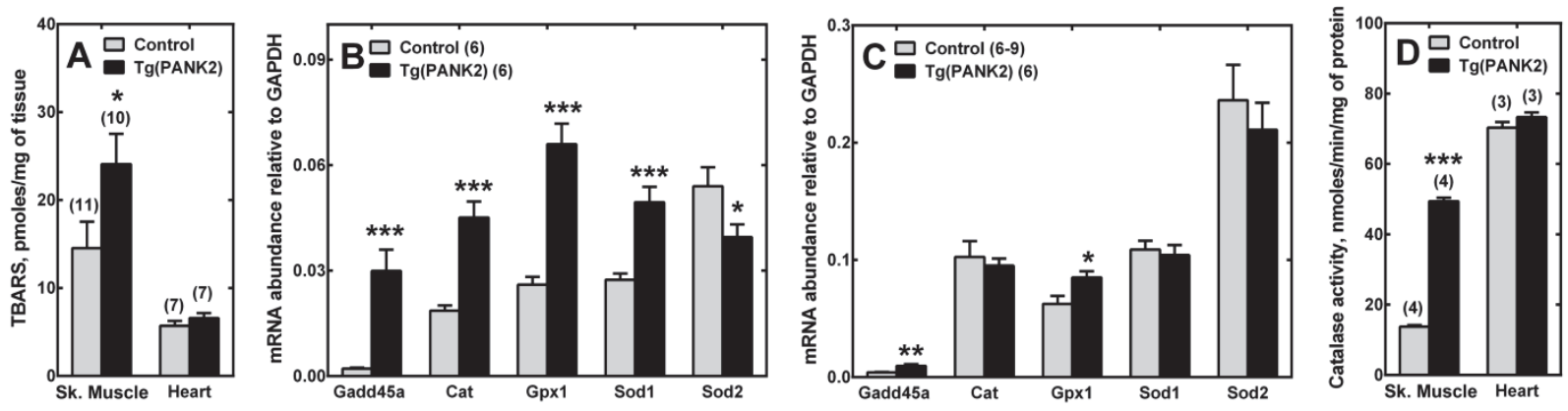

Figure 9. Increased markers of oxidative stress in skeletal muscle of $\mathrm{Tg}$ (PANK2) mice

(A) Thiobarbituric reactive species (TBARS) were elevated in the hamstring muscles but not in the hearts of $\mathrm{Tg}($ PANK2) mice compared to controls. RT-qPCR analysis of enzymes known to be involved in the response to oxidative damage in $(B)$ hamstrings and $(C)$ hearts showed a robust upregulation in skeletal muscle. $(D)$, Elevated catalase activity in $\operatorname{Tg}(P A N K 2)$ hamstring muscles. The number of mice/genotype used for each experiment is indicated in parenthesis, and the plotted data represent the mean \pm the standard error. Student's t-test was used to determine significance: ${ }^{*}, p<0.05 ;{ }^{* *}, p<0.01 ;{ }^{* * *}, p<0.001$.

\section{Conclusions}

$\mathrm{CoA}$ is a tightly regulated cofactor. The importance of maintaining sufficient levels of CoA to support energy metabolism in tissues and organs was manifested in multiple mouse lines with reduced CoA synthesis $(13,15,61)$ and illustrated by human neurological diseases that are linked to mutations in CoA biosynthetic genes $(19,62)$. This work demonstrates that excess CoA can also be deleterious to organ function. The $\operatorname{Tg}(P A N K 2)$ mice exhibit a complex phenotype characterized by a small body size, a reduction in skeletal muscle mass and exercise performance associated with elevated CoA in the limb muscles. Skeletal muscles in $\operatorname{Tg}(P A N K 2)$ mice contained 2-3 times more CoA than control mice and exhibited abnormal mitochondrial morphology and reduced complex I activity and content, resulting in decreased ATP levels and increased oxidative stress. Overexpression of PANK2 did not lead to increased CoA levels in all tissues, due to differences in the levels of transgene expression and possibly coupled with the predicted tight feedback regulation of PANK2 by acetyl-CoA and other CoA thioesters. Indeed, PANK2 expression was significantly elevated in both the hearts and skeletal muscles of the $\operatorname{Tg}(P A N K 2)$ animals but total CoA levels were not elevated in the heart, consistent with high basal levels of acetyl-CoA that can feedback inhibit PANK2 activity in this organ. The feedback inhibition was recently revealed to be highly cooperative, meaning that the degree of inhibition is an exponential function of the amount of acetyl-CoA (46). The transgenic hearts exhibited normal gross morphology with some irregularity in the cristae content of mitochondria; however, ATP content and complex I activity in the $\operatorname{Tg}(P A N K 2)$ hearts were comparable to wild-type hearts, indicating that the mitochondria were fully functional. Furthermore, unlike the skeletal muscles, only minor signs of oxidative stress were detected in the heart of $\operatorname{Tg}(P A N K 2)$ mice. Collectively, these results strongly support the conclusion that the substantial changes in transgenic skeletal muscle were driven by the elevation in muscle CoA and not by the expression of the PANK2 protein per se. 
The phenotype of the $\operatorname{Tg}(P A N K 2)$ mice underscores the importance of CoA regulation. Therapies that bypass the regulatory PanK step hold promise for the treatment of PKAN as they could potentially restore CoA to levels able to support neuronal function. However, organs where PANK2 is a minor isoform and CoA levels are not affected by the PKAN-causing mutations could experience a net increase in CoA synthesis and CoA levels. Under conditions of supraphysiological CoA synthesis, organs with a high abundance of CoAdegrading enzymes, such as liver and kidneys, might be able to maintain CoA homeostasis by increasing CoA turnover $(4,12)$. In the skeletal muscle of $\mathrm{Tg}(P A N K 2)$ mice CoA degradation was either not induced or unable to cope with the large increase in CoA synthesis, resulting in significantly higher steady-state CoA levels and in a combination of abnormalities that overall decreased muscle strength and performance. The smaller size of the $\mathrm{Tg}(P A N K 2)$ pups at four weeks of age suggests that the increase in CoA levels and the muscle phenotype could already be present in very early development during gestation. This represents an important difference with respect to PKAN patients where the onset of the neurological symptoms occurs in early childhood or adulthood, at which time therapies able to increase CoA levels would be initiated. In spite of this difference, the phenotype of the $\operatorname{Tg}(P A N K 2)$ mice shows that sustained elevation of tissue CoA can be deleterious for skeletal muscle and should guide the development and optimization of potential gene replacement therapies for PKAN disease.

\section{Acknowledgements}

This work was supported by West Virginia University's School of Medicine startup foundation funding (R.L.), National Institutes of Health Grants NS091590 (R.L.), GM119528 (R.L.), HL128485 (J.M.H.), NEI025536 (P.S.) and GM062896 (S.J.), Cancer Center Support Grant CA21765 (S.J.), American Lebanese Syrian Associated Charities (S.J.), Department of Defense Grant BC142286 (P.S.). We thank Lois Richmond, Caroline Pate, Karen Miller, Jina Wang, Katie Wells, Pamela Jackson, Matthew Frank, the Genomics Core Facilities at West Virginia University and Marshall University, and the Veterinary Pathology Core Facility, the Transgenic Animal Core Facility and Electron Microscopy Division of the Cell and Tissue Imaging Center at St. Jude Children's Hospital for their expert technical assistance. We are grateful to Dr. Stephen E. Alway at West Virginia University for his critical reading of the manuscript. 


\section{References}

1. Leonardi, R., Zhang, Y. M., Rock, C. O., and Jackowski, S. (2005) Coenzyme A: back in action. Progress in lipid research 44, 125-153

2. Zhang, Y. M., Rock, C. O., and Jackowski, S. (2005) Feedback regulation of murine pantothenate kinase 3 by coenzyme A and coenzyme A thioesters. The Journal of biological chemistry 280, 3259432601

3. Robishaw, J. D., Berkich, D., and Neely, J. R. (1982) Rate-limiting step and control of coenzyme A synthesis in cardiac muscle. The Journal of biological chemistry 257, 10967-10972

4. Zano, S. P., Pate, C., Frank, M., Rock, C. O., and Jackowski, S. (2015) Correction of a genetic deficiency in pantothenate kinase 1 using phosphopantothenate replacement therapy. Molecular genetics and metabolism 116, 281-288

5. Rock, C. O., Park, H. W., and Jackowski, S. (2003) Role of feedback regulation of pantothenate kinase (CoaA) in control of coenzyme A levels in Escherichia coli. Journal of bacteriology 185, 3410-3415

6. Rock, C. O., Karim, M. A., Zhang, Y. M., and Jackowski, S. (2002) The murine pantothenate kinase (Pank1) gene encodes two differentially regulated pantothenate kinase isozymes. Gene 291, 35-43

7. Rock, C. O., Calder, R. B., Karim, M. A., and Jackowski, S. (2000) Pantothenate kinase regulation of the intracellular concentration of coenzyme A. The Journal of biological chemistry 275, 1377-1383

8. Ofman, R., Speijer, D., Leen, R., and Wanders, R. J. (2006) Proteomic analysis of mouse kidney peroxisomes: identification of RP2p as a peroxisomal nudix hydrolase with acyl-CoA diphosphatase activity. The Biochemical journal 393, 537-543

9. Gasmi, L., and McLennan, A. G. (2001) The mouse Nudt7 gene encodes a peroxisomal nudix hydrolase specific for coenzyme A and its derivatives. The Biochemical journal 357, 33-38

10. Zhou, B., Westaway, S. K., Levinson, B., Johnson, M. A., Gitschier, J., and Hayflick, S. J. (2001) A novel pantothenate kinase gene (PANK2) is defective in Hallervorden-Spatz syndrome. Nature genetics 28, 345-349

11. Zhang, Y. M., Rock, C. O., and Jackowski, S. (2006) Biochemical properties of human pantothenate kinase 2 isoforms and mutations linked to pantothenate kinase-associated neurodegeneration. The Journal of biological chemistry 281, 107-114

12. Zhang, Y. M., Chohnan, S., Virga, K. G., Stevens, R. D., Ilkayeva, O. R., Wenner, B. R., Bain, J. R., Newgard, C. B., Lee, R. E., Rock, C. O., and Jackowski, S. (2007) Chemical knockout of pantothenate kinase reveals the metabolic and genetic program responsible for hepatic coenzyme A homeostasis. Chemistry \& biology 14, 291-302

13. Leonardi, R., Rehg, J. E., Rock, C. O., and Jackowski, S. (2010) Pantothenate kinase 1 is required to support the metabolic transition from the fed to the fasted state. PloS one 5, e11107

14. Kuo, Y. M., Hayflick, S. J., and Gitschier, J. (2007) Deprivation of pantothenic acid elicits a movement disorder and azoospermia in a mouse model of pantothenate kinase-associated neurodegeneration. Journal of inherited metabolic disease 30, 310-317

15. Garcia, M., Leonardi, R., Zhang, Y. M., Rehg, J. E., and Jackowski, S. (2012) Germline deletion of pantothenate kinases 1 and 2 reveals the key roles for CoA in postnatal metabolism. PloS one 7 , e40871

16. Leonardi, R., Zhang, Y. M., Lykidis, A., Rock, C. O., and Jackowski, S. (2007) Localization and regulation of mouse pantothenate kinase 2. FEBS letters 581, 4639-4644

17. Kotzbauer, P. T., Truax, A. C., Trojanowski, J. Q., and Lee, V. M. (2005) Altered neuronal mitochondrial coenzyme A synthesis in neurodegeneration with brain iron accumulation caused by abnormal processing, stability, and catalytic activity of mutant pantothenate kinase 2. The Journal of neuroscience : the official journal of the Society for Neuroscience 25, 689-698

18. Hong, B. S., Senisterra, G., Rabeh, W. M., Vedadi, M., Leonardi, R., Zhang, Y. M., Rock, C. O., Jackowski, S., and Park, H. W. (2007) Crystal structures of human pantothenate kinases. Insights into allosteric regulation and mutations linked to a neurodegeneration disorder. The Journal of biological chemistry 282, 27984-27993

19. Dusi, S., Valletta, L., Haack, T. B., Tsuchiya, Y., Venco, P., Pasqualato, S., Goffrini, P., Tigano, M., Demchenko, N., Wieland, T., Schwarzmayr, T., Strom, T. M., Invernizzi, F., Garavaglia, B., Gregory, A., 
Sanford, L., Hamada, J., Bettencourt, C., Houlden, H., Chiapparini, L., Zorzi, G., Kurian, M. A., Nardocci, N., Prokisch, H., Hayflick, S., Gout, I., and Tiranti, V. (2014) Exome sequence reveals mutations in CoA synthase as a cause of neurodegeneration with brain iron accumulation. American journal of human genetics 94, 11-22

20. Shumar, S. A., Fagone, P., Alfonso-Pecchio, A., Gray, J. T., Rehg, J. E., Jackowski, S., and Leonardi, R. (2015) Induction of Neuron-Specific Degradation of Coenzyme A Models Pantothenate KinaseAssociated Neurodegeneration by Reducing Motor Coordination in Mice. PloS one 10, e0130013

21. Srinivasan, B., Baratashvili, M., van der Zwaag, M., Kanon, B., Colombelli, C., Lambrechts, R. A., Schaap, O., Nollen, E. A., Podgorsek, A., Kosec, G., Petkovic, H., Hayflick, S., Tiranti, V., Reijngoud, D. J., Grzeschik, N. A., and Sibon, O. C. (2015) Extracellular 4'-phosphopantetheine is a source for intracellular coenzyme A synthesis. Nature chemical biology 11, 784-792

22. Alfonso-Pecchio, A., Garcia, M., Leonardi, R., and Jackowski, S. (2012) Compartmentalization of mammalian pantothenate kinases. PloS one 7, e49509

23. Oliver, I. T. (1955) A spectrophotometric method for the determination of creatine phosphokinase and myokinase. The Biochemical journal 61, 116-122

24. Leonardi, R., Rock, C. O., and Jackowski, S. (2014) Pank1 deletion in leptin-deficient mice reduces hyperglycaemia and hyperinsulinaemia and modifies global metabolism without affecting insulin resistance. Diabetologia 57, 1466-1475

25. Niwa, H., Yamamura, K., and Miyazaki, J. (1991) Efficient selection for high-expression transfectants with a novel eukaryotic vector. Gene 108, 193-199

26. Kim, D., Langmead, B., and Salzberg, S. L. (2015) HISAT: a fast spliced aligner with low memory requirements. Nature methods 12, 357-360

27. Stites, T., Storms, D., Bauerly, K., Mah, J., Harris, C., Fascetti, A., Rogers, Q., Tchaparian, E., Satre, M., and Rucker, R. B. (2006) Pyrroloquinoline quinone modulates mitochondrial quantity and function in mice. The Journal of nutrition 136, 390-396

28. Bradford, M. M. (1976) A rapid and sensitive method for the quantitation of microgram quantities of protein utilizing the principle of protein-dye binding. Analytical biochemistry 72, 248-254

29. Shangari, N., and O'Brien, P. J. (2006) Catalase activity assays. Current protocols in toxicology / editorial board, Mahin D. Maines Chapter 7, Unit 77 1-15

30. Ohkawa, H., Ohishi, N., and Yagi, K. (1979) Assay for lipid peroxides in animal tissues by thiobarbituric acid reaction. Analytical biochemistry 95, 351-358

31. Frezza, C., Cipolat, S., and Scorrano, L. (2007) Organelle isolation: functional mitochondria from mouse liver, muscle and cultured fibroblasts. Nature protocols 2, 287-295

32. Baseler, W. A., Dabkowski, E. R., Jagannathan, R., Thapa, D., Nichols, C. E., Shepherd, D. L., Croston, T. L., Powell, M., Razunguzwa, T. T., Lewis, S. E., Schnell, D. M., and Hollander, J. M. (2013) Reversal of mitochondrial proteomic loss in Type 1 diabetic heart with overexpression of phospholipid hydroperoxide glutathione peroxidase. American journal of physiology. Regulatory, integrative and comparative physiology 304, R553-565

33. Trounce, I. A., Kim, Y. L., Jun, A. S., and Wallace, D. C. (1996) Assessment of mitochondrial oxidative phosphorylation in patient muscle biopsies, lymphoblasts, and transmitochondrial cell lines. Methods in enzymology 264, 484-509

34. Dabkowski, E. R., Williamson, C. L., and Hollander, J. M. (2008) Mitochondria-specific transgenic overexpression of phospholipid hydroperoxide glutathione peroxidase (GPx4) attenuates ischemia/reperfusion-associated cardiac dysfunction. Free radical biology \& medicine 45, 855-865

35. Dabkowski, E. R., Williamson, C. L., Bukowski, V. C., Chapman, R. S., Leonard, S. S., Peer, C. J., Callery, P. S., and Hollander, J. M. (2009) Diabetic cardiomyopathy-associated dysfunction in spatially distinct mitochondrial subpopulations. American journal of physiology. Heart and circulatory physiology 296, H359-369

36. Dabkowski, E. R., Baseler, W. A., Williamson, C. L., Powell, M., Razunguzwa, T. T., Frisbee, J. C., and Hollander, J. M. (2010) Mitochondrial dysfunction in the type 2 diabetic heart is associated with alterations in spatially distinct mitochondrial proteomes. American journal of physiology. Heart and circulatory physiology 299, H529-540

37. Ritov, V. B., Menshikova, E. V., He, J., Ferrell, R. E., Goodpaster, B. H., and Kelley, D. E. (2005) Deficiency of subsarcolemmal mitochondria in obesity and type 2 diabetes. Diabetes 54, 8-14 
38. Pullman, M. E., Penefsky, H. S., Datta, A., and Racker, E. (1960) Partial resolution of the enzymes catalyzing oxidative phosphorylation. I. Purification and properties of soluble dinitrophenol-stimulated adenosine triphosphatase. The Journal of biological chemistry 235, 3322-3329

39. Feniouk, B. A., Suzuki, T., and Yoshida, M. (2007) Regulatory interplay between proton motive force, ADP, phosphate, and subunit epsilon in bacterial ATP synthase. The Journal of biological chemistry 282, 764-772

40. Okabe, M., Ikawa, M., Kominami, K., Nakanishi, T., and Nishimune, Y. (1997) 'Green mice' as a source of ubiquitous green cells. FEBS letters 407, 313-319

41. Takeuchi, K., Sereemaspun, A., Inagaki, T., Hakamata, Y., Kaneko, T., Murakami, T., Takahashi, M., Kobayashi, E., and Ookawara, S. (2003) Morphologic characterization of green fluorescent protein in embryonic, neonatal, and adult transgenic rats. The anatomical record. Part A, Discoveries in molecular, cellular, and evolutionary biology 274, 883-886

42. Ke, B. X., Llanos, R. M., Wright, M., Deal, Y., and Mercer, J. F. (2006) Alteration of copper physiology in mice overexpressing the human Menkes protein ATP7A. American journal of physiology. Regulatory, integrative and comparative physiology 290, R1460-1467

43. Hortnagel, K., Prokisch, H., and Meitinger, T. (2003) An isoform of hPANK2, deficient in pantothenate kinase-associated neurodegeneration, localizes to mitochondria. Human molecular genetics 12, 321327

44. Dansie, L. E., Reeves, S., Miller, K., Zano, S. P., Frank, M., Pate, C., Wang, J., and Jackowski, S. (2014) Physiological roles of the pantothenate kinases. Biochemical Society transactions 42, 10331036

45. Leonardi, R., Rock, C. O., Jackowski, S., and Zhang, Y. M. (2007) Activation of human mitochondrial pantothenate kinase 2 by palmitoylcarnitine. Proceedings of the National Academy of Sciences of the United States of America 104, 1494-1499

46. Subramanian, C., Yun, M. K., Yao, J., Sharma, L. K., Lee, R. E., White, S. W., Jackowski, S., and Rock, C. O. (2016) Allosteric Regulation of Mammalian Pantothenate Kinase. The Journal of biological chemistry 291, 22302-22314

47. Noland, R. C., Koves, T. R., Seiler, S. E., Lum, H., Lust, R. M., Ilkayeva, O., Stevens, R. D., Hegardt, F. G., and Muoio, D. M. (2009) Carnitine insufficiency caused by aging and overnutrition compromises mitochondrial performance and metabolic control. The Journal of biological chemistry 284, 2284022852

48. Choi, Y. R., Fogle, P. J., Clarke, P. R., and Bieber, L. L. (1977) Quantitation of water-soluble acylcarnitines and carnitine acyltransferases in rat tissues. The Journal of biological chemistry 252, 7930-7931

49. Brass, E. P., and Hoppel, C. L. (1980) Relationship between acid-soluble carnitine and coenzyme A pools in vivo. The Biochemical journal 190, 495-504

50. Seiler, S. E., Koves, T. R., Gooding, J. R., Wong, K. E., Stevens, R. D., Ilkayeva, O. R., Wittmann, A. H., DeBalsi, K. L., Davies, M. N., Lindeboom, L., Schrauwen, P., Schrauwen-Hinderling, V. B., and Muoio, D. M. (2015) Carnitine Acetyltransferase Mitigates Metabolic Inertia and Muscle Fatigue during Exercise. Cell metabolism 22, 65-76

51. Carter, A. L., Lennon, D. L., and Stratman, F. W. (1981) Increased acetyl carnitine in rat skeletal muscle as a result of high-intensity short-duration exercise. Implications in the control of pyruvate dehydrogenase activity. FEBS letters 126, 21-24

52. Verkaart, S., Koopman, W. J., van Emst-de Vries, S. E., Nijtmans, L. G., van den Heuvel, L. W., Smeitink, J. A., and Willems, P. H. (2007) Superoxide production is inversely related to complex I activity in inherited complex I deficiency. Biochimica et biophysica acta 1772, 373-381

53. Miwa, S., Jow, H., Baty, K., Johnson, A., Czapiewski, R., Saretzki, G., Treumann, A., and von Zglinicki, T. (2014) Low abundance of the matrix arm of complex I in mitochondria predicts longevity in mice. Nature communications 5, 3837

54. Keeney, P. M., Xie, J., Capaldi, R. A., and Bennett, J. P., Jr. (2006) Parkinson's disease brain mitochondrial complex I has oxidatively damaged subunits and is functionally impaired and misassembled. The Journal of neuroscience : the official journal of the Society for Neuroscience 26, 5256-5264 
55. Han, E. S., Muller, F. L., Perez, V. I., Qi, W., Liang, H., Xi, L., Fu, C., Doyle, E., Hickey, M., Cornell, J., Epstein, C. J., Roberts, L. J., Van Remmen, H., and Richardson, A. (2008) The in vivo gene expression signature of oxidative stress. Physiological genomics 34, 112-126

56. Ebert, S. M., Dyle, M. C., Kunkel, S. D., Bullard, S. A., Bongers, K. S., Fox, D. K., Dierdorff, J. M., Foster, E. D., and Adams, C. M. (2012) Stress-induced skeletal muscle Gadd45a expression reprograms myonuclei and causes muscle atrophy. The Journal of biological chemistry 287, 2729027301

57. Carroll, J., Fearnley, I. M., Skehel, J. M., Shannon, R. J., Hirst, J., and Walker, J. E. (2006) Bovine complex I is a complex of 45 different subunits. The Journal of biological chemistry 281, 32724-32727

58. Mimaki, M., Wang, X., McKenzie, M., Thorburn, D. R., and Ryan, M. T. (2012) Understanding mitochondrial complex I assembly in health and disease. Biochimica et biophysica acta 1817, 851-862

59. Carroll, J., Fearnley, I. M., Skehel, J. M., Runswick, M. J., Shannon, R. J., Hirst, J., and Walker, J. E. (2005) The post-translational modifications of the nuclear encoded subunits of complex I from bovine heart mitochondria. Molecular \& cellular proteomics : MCP 4, 693-699

60. Triepels, R., Smeitink, J., Loeffen, J., Smeets, R., Buskens, C., Trijbels, F., and van den Heuvel, L. (1999) The human nuclear-encoded acyl carrier subunit (NDUFAB1) of the mitochondrial complex I in human pathology. Journal of inherited metabolic disease 22, 163-173

61. Kuo, Y. M., Duncan, J. L., Westaway, S. K., Yang, H., Nune, G., Xu, E. Y., Hayflick, S. J., and Gitschier, J. (2005) Deficiency of pantothenate kinase 2 (Pank2) in mice leads to retinal degeneration and azoospermia. Human molecular genetics 14, 49-57

62. Schneider, S. A., Dusek, P., Hardy, J., Westenberger, A., Jankovic, J., and Bhatia, K. P. (2013) Genetics and Pathophysiology of Neurodegeneration with Brain Iron Accumulation (NBIA). Current neuropharmacology 11, 59-79 


\section{TABLES}

Table 1. Blood parameters of control and $\operatorname{Tg}(P A N K 2)$ mice

Serum analysis of control and $\mathrm{Tg}(P A N K 2)$ male mice. Serum was collected from animals fed ad libitum, unless otherwise stated. Values represent the average \pm standard error, and the number of mice analyzed is indicated in parenthesis. The Student's t-test was used for the statistical analysis of the data. ${ }^{*}, p<0.05 ;{ }^{* *}, p$ $<0.001$.

\begin{tabular}{lll}
\hline \multicolumn{1}{c}{ Blood Parameter } & \multicolumn{1}{c}{ Control } & \multicolumn{1}{c}{ Tg(PANK2) } \\
\hline Glucose, mg/dl & $110 \pm 5(11)$ & $90 \pm 5(10)^{\star *}$ \\
Glucose, fasted, mg/dl & $68 \pm 3(14)$ & $59 \pm 4(10, \mathrm{p}=0.06)$ \\
Insulin, $\mathrm{ng} / \mathrm{ml}$ & $0.54 \pm 0.13(11)$ & $0.21 \pm 0.03(9)^{*}$ \\
Insulin, fasted, $\mathrm{ng} / \mathrm{ml}$ & $0.18 \pm 0.08(6)$ & $0.18 \pm 0.03(5)$ \\
Calcium, mg/dl & $10 \pm 1(6)$ & $10 \pm 2(4)$ \\
Potassium, mM & $6.9 \pm 0.7(6)$ & $5.9 \pm 0.4(4)$ \\
Creatinine, mg/dl & $0.16 \pm 0.02(5)$ & $0.13 \pm 0.02(4)$ \\
Blood urea nitrogen (BUN), mg/dl & $31 \pm 4(6)$ & $20 \pm 4(4)$ \\
Alanine aminotransferase (ALT), U/l & $67 \pm 20(5)$ & $46 \pm 11(4)$ \\
Aspartate aminotransferase (AST), U/l & $167 \pm 26(5)$ & $176 \pm 18(4)$ \\
Creatine phosphokinase (CPK), U/l & $20 \pm 3(9)$ & $38 \pm 10(11)$ \\
Triglycerides, mg/dl & $97 \pm 11(5)$ & $111 \pm 17(4)$ \\
Lactate, mM & $12 \pm 1(4)$ & $11 \pm 1(4)$ \\
\hline
\end{tabular}


Table 2. Tissue pantothentate kinase activities in control and $\mathrm{Tg}(P A N K 2)$ mice

Tissue samples were removed from 10-week old control and $\operatorname{Tg}(P A N K 2)$ mice, soluble extracts were prepared, and the total PanK specific activity was determined as described under "Materials and Methods." Values represent the average \pm the standard error, and the number of mice analyzed is indicated in parenthesis. The Student's t-test was used for the statistical analysis of the data. ${ }^{*}, p<0.05 ;{ }^{* *}, p<0.01 ;{ }^{* * *}, p<0.001$.

\begin{tabular}{llll}
\hline \multirow{2}{*}{ Tissue } & \multicolumn{2}{l}{ Total PanK Activity $(\mathbf{p m o l e s} / \mathrm{min} / \mathrm{mg})$} \\
\cline { 2 - 4 } & Control & Tg(PANK2) & $\begin{array}{l}\text { Fold Change } \\
\text { Tg(PANK2)/Control }\end{array}$ \\
\hline Liver & $11.03 \pm 0.70(4)$ & $14.94 \pm 1.14(4))^{* * *}$ & 1.4 \\
Brain & $7.55 \pm 1.00(4)$ & $16.20 \pm 2.68(4)^{* *}$ & 2.1 \\
Heart & $1.91 \pm 0.25(3)$ & $334.50 \pm 36.11(4)^{* * *}$ & 175.1 \\
Hamstring & $0.25 \pm 0.04(3)$ & $34.33 \pm 3.11(3)^{* * *}$ & 137.3 \\
Triceps surae & $0.10 \pm 0.01(3)$ & $14.47 \pm 0.43(3)^{* * *}$ & 144.7 \\
Quadriceps & $0.20 \pm 0.03(3)$ & $31.54 \pm 0.92(3)^{* * *}$ & 157.7 \\
\hline
\end{tabular}

